(Contribution from the Rogers Laboratory of Physics, Massachusetts Institute of Technology)

\title{
THE ESTABLISHING OF THE ABSOLUTE TEMPER- ATURE SCALE BELOW THE MELTING POINT OF ICE
}

By Frederick G Keyes, Bailey Townshend and Louis H. Young

Introduction.

\section{CONTENTS}

Part I

II. Definition of Temperature by the Constant Volume Gas Thermometer. Calculation of Temperature from the Observed Measurements.

III The Relation between the Constant Volume Gas Scale and the Kelvin Thermodynamic Scale.

(a) The Equation of State for Gases. Evidence that Pressure is a Linear Function of the Temperature at Constant Volume.

(b) The Normal Sulfur Boiling Point

(c) Discussion of the Usual Corrections to the Constant Volume Thermometer.

(d) Analysis of the Isothermals and Isometrics of Hydrogen. The Equation of State for Hydrogen. Joule-Thomson Coefficients and Inversion Temperatures of Hydrogen

IV. Description of the Apparatus

V. Sources of Error

VI. Description of the Experiments.

(a) Indurect Determination of the Dead Space Volume

(b) Coefficient of Pressure Increase of Nitrogen.

(c) The Diffiuston of Helium and Hydrogen Through Quartz.

(d) Measurements with the Nitrogen Thermometer Thermocouple Calibration Platınum Resistance Thermometer Comparison. Boiling Points of Carbon Dioxide and Oxygen (preliminary).

(e) Measurements with the Hydrogen Thermometer. Platinum Resistance Thermometer Comparison Comparison of Nitrogen and Hydrogen Thermometers Bolling Point of Oxygen. Boiling Point of Carbon Dioxide.

\section{Part II}

Freezing Points of Certain Organic Liquids and of Mercury and Ammonia.

The Method

The Results

Summary. 


\section{Introduction}

The field of experimental inquiry at low temperatures relative to the properties of matter is one which has benefited largely from the researches conducted at Professor Onnes' laboratory in Leiden Here there have been developed ingenious methods for attacking the many vaned problems among which the most fundamental is undoubtedly the devising of convenient and accurate temperature-measuring instruments, and the relating of their indications to the absolute temperature scale Systematic investigations of notable importance in the measurement of low temperatures have also been carred out at the Reichsanstalt The status of the general problem has, however, not reached that stage where the calibration of temperature indicators of the secondary class, such as the electrical resistance, pentane, or thermoelement thermometers, can be safely relied upon without the use of the gas thermometer The fixed points, for example, worthy of most confidence are the normal bolling points of oxygen and carbon dioxide; the former of which hes at about $-183^{\circ}$ and the latter at about $-785^{\circ}$ Evidently more fixed points are needed, and, moreover, the investigations of Henning have shown that the platinum resistance thermometer departs in its indications widely from the Callendar formula which is satisfactory above the 1ce point Cardoso in the case of the pentane thermometer has also pointed out special difficulties attending the use of this thermometer, so that confidence in the low temperature investigations being carried out in this Institute could only be realized by an independent study of the low-temperature scale

The many careful researches on gas thermometry and general methods of temperature measurement have dealt in the main, of course, with ordinary and high temperatures, while the region below the ice point has not as yet received as much development as is necessary Apart, moreover, from the immediate need of thermometric standardization below $0^{\circ} \mathrm{C}$ collateral problems have deterred progress in this direction Chief of these is the relative difficulty of producing low temperatures and the extreme difficulty of maintaining these temperatures constant over considerable periods of time In gas thermometry there is 
also the uncertainty with regard to the expansion of the container of the thermometric substance, and the effect of aggravated adsorption of the gas on the walls of the thermometer bulb. Indeed, it will be shown that this latter effect may be very appreciable and leads to serous error in the case of gases readily adsorbed For some time this laboratory has had developed an improved type of cryostat wherein constancy of temperature of $001^{\circ} \mathrm{C}$ is easily attainable, and certain other instrumental refinements, making 1 t worth while to study the subject independently, from a slightly different standpoint, and with a view to increasing the accuracy of low temperature measurements

The investigation set forth in the following pages has had for its primary objects first, a study of the gas thermometer of constant volume between $0^{\circ} \mathrm{C}$ and the bolling point of oxygen $\left(-183^{\circ}\right)$ and, second, the determination of certain fixed points within this range serving the same purpose as those now available for calibration of secondary instruments at temperatures above the ice point Incident hereto was, of course, a comparison of the platinum resistance thermometer and copper-constantan thermocouple used in other low temperature investigations with the hydrogen constant volume thermometric scale

II Calculation of Temperature from Observed Measurements with the Constant Volume Gas Thermometer. Centigrade temperature is defined by the equation

$$
t=\frac{p-p_{0}}{\epsilon_{0} p_{0}}
$$

where $p$ and $p_{0}$ are the pressures exerted by the gas at $t^{\circ}$ and $0^{\circ}$ respectively, and $t_{0}^{t}$ is the mean coefficient of pressure increase at constant volume between $0^{\circ}$ and $t^{\circ}$ The two fixed points defined by the freezing point and normal boiling point of water are, of course, the usual temperature interval used

Since the volume of the container is not absolutely constant, 
owing to temperature dilation and pressure dilation changes, it is necessary to modify (1) to

$$
t=\frac{p_{v_{0}}^{v}-p_{0}}{t_{v} p_{0}}
$$

where $v$ and $v_{0}$ are the true volumes at $t^{\circ}$ and $0^{\circ}$

The system contaning the gas comprises the bulb of the thermometer and a certain length of capillary connecting the bulb to the manometer Let the volume of this latter part be designated as "dead space" and the following symbols adopted

$V_{\circ}=$ volume of bulb at $0^{\circ}$

$V=$ volume of bulb at $t^{\circ}$

$v_{s}=$ volume of dead space at room temperature ${ }^{1}$

$\beta=$ coefficient of cubical expansion of bulb material

$\delta=$ coefficient of expansion of the bulb with internal pressure (c c. per $\mathrm{mm}$ )

Then (2) becomes

$$
t=\frac{1}{\epsilon_{0} p}\left[p \frac{V_{0}+v_{s}}{V_{0}+v_{s}}-p_{\circ}\right]
$$

or

$$
t=\frac{1}{\epsilon_{0} p_{0}}\left[p\left\{1+\frac{\beta t V_{0}+\delta\left(p-p_{0}\right)}{V_{\circ}+v_{s}}\right\}-p_{0}\right] \ldots
$$

\section{Dead Space Correction}

In the above formula the pressures are those which the gas would exert if the entire volume were at $t^{\circ}$ and $0^{\circ}$ respectively In practice, the bulb and a certain portion of the capillary are at the temperature of the bath, while the remainder of the dead space may be divided into parts at $t^{\circ}{ }_{1}, t_{2}^{\circ}$, etc The manner of computing $p$ from the corrected observed pressure, $p^{I}$, is as follows Let

1 The volume of the dead space is relatively small and since the temperature of the greater part of it is always within a few degrees of the same value it is not necessary to consider its volume change due to temperature and pressure. 
$V=$ volume of the bulb at the temperature of the bath, $t$. $v_{1}, v_{2}$, etc $=$ volumes of dead space at corresponding temperature, $t_{1}, t_{2}$, etc

$\epsilon=$ approximate coefficient of expansion of a gas, 000366

Then, making use of the fact that the total mass of gas in the apparatus is constant.

$$
p \frac{\left(V+v_{1}+v_{2}+\quad\right)}{1+\epsilon t}=\frac{p^{\mathrm{I}} V}{1+\epsilon t}+\frac{p^{\mathrm{I}} v_{1}}{1+\epsilon t_{1}}+\frac{p^{\mathrm{I}} v_{2}}{1+\epsilon t_{2}}+\ldots
$$

from which it follows that.

$p-p^{\mathrm{I}}=p^{\mathrm{I}}\left\{\frac{v_{1}\left(1+\epsilon t_{2}\right)\left(t-t_{1}\right) \epsilon+v_{2}\left(1+\epsilon t_{2}\right)\left(t_{1}-t_{2}\right) \epsilon}{\left(V+v_{1}+v_{2}\right)\left(1+\epsilon t_{1}\right)\left(1+\epsilon t_{2}\right)}\right\}$

where the dead space is considered in this example as consisting of two portions, $v_{1}$ and $v_{2}$

\section{Correction of the Observed Pressure}

The pressures are here expressed in millimeters of mercury To obtain $p^{\mathrm{T}}$ the actually observed height must be corrected to millimeters of $\mathrm{Hg}$ at $0^{\circ}$, sea level, and $45^{\circ}$ latitude and also for difference in level of the bulb and contact point of the manometer ${ }^{2}$ The former involves a knowledge of calibration errors and coefficient of expansion of the cathetometer scale Let

$\gamma=$ coefficient of linear expansion of cathetometer scale

$\sigma=$ scale error per millimeter as compared with standard scale at $20^{\circ}$

$p^{\mathrm{rv}}=$ actually observed pressure

$p^{\mathrm{III}}=$ pressure corrected for cathetometer scale errors

$t_{r}=$ room temperature

then

$$
p^{\mathrm{III}}=p^{\mathrm{IV}}\left\{1+\sigma+\gamma\left(t_{r}-20\right)\right\}
$$

2 A correction for capillary depression may be eliminated by using manometer tubes of sufficiently large and uniform diameter. 
Further let

$t_{m}=$ temperature of mercury column of manometer.

$a=$ mean coefficient of expansion of mercury $0^{\circ}$ to $t_{m}^{o}$

$g=$ acceleration of gravity at place of observation.

$G=$ standard acceleration of gravity

$p^{\mathrm{II}}=$ pressure corrected for scale errors and reduced to standard conditions

Then

$$
p^{\mathrm{II}}=p^{\mathrm{m}}\left(\frac{g}{G}\right)\left(1-a t_{m}\right)
$$

The level correction is significant where the difference in level is several hundred millimeters Let

$l=$ height of bulb above contact point of manometer.

$\rho_{g}=$ density of the gas at temperature of column 1

$\rho_{m}=$ density of mercury at $0^{\circ}$

$p=$ pressure corrected for scale errors, reduced to standard conditions, and corrected for difference in gas level

Then

$$
p^{\mathrm{I}}=p^{\mathrm{II}}-\frac{\rho_{g} l}{\rho_{m}}
$$

Combining into one formula the various corrections applicable to the observed height, $p,{ }^{\mathrm{IV}}$ and excepting the dead space correction, there results

$$
p^{\mathrm{I}}=p^{\mathrm{IV}}\left\{1+\sigma+\gamma\left(t_{r}-20\right)\right\}\left(\frac{g}{G}\right)\left(1-a t_{m}\right)-\frac{\rho_{g} l}{\rho_{m}}
$$

Formulæ (3), (4) and (6) thus serve to calculate the centigrade temperatures from the actually observed difference in height of the mercury columns of the manometer, it being assumed that the space above the variable column is exhausted

A quantitative discussion of sources of error will be given in connection with the description of the experimental procedure It w1ll be, however, instructive at this point to present a sample calculation illustrating the magnitudes of the various corrections. 
The following is a measurement of the temperature of liquid oxygen (above its normal boiling point) by means of the hydrogen thermometer

\begin{tabular}{c|c|c|c}
\hline $\begin{array}{c}p^{\mathrm{Iv}} \\
m m\end{array}$ & $t_{m}$ & $t_{r}$ & $\begin{array}{c}T_{2 m e} \\
(3 / 30 / 22)\end{array}$ \\
\hline 255430 & 2316 & 250 & 1050 \\
255423 & 2317 & 250 & 52 \\
233430 & 2318 & 250 & 57 \\
255435 & 2320 & 250 & 59 \\
\hline
\end{tabular}

For the correction for scale and reduction of mercury column to standard conditions (5a), (5b),

$$
\begin{aligned}
p^{\mathrm{II}}= & 255430\left[1+20 \times 10^{-6}+11 \times 10^{-6}(25-10)\right][1-0000255] \\
& {\left[1-1809 \times 10^{-4}(2318)\right] } \\
= & 254313 \mathrm{~mm}
\end{aligned}
$$

For the correction for difference in level of the bulb and contact point of manometer $(5 \mathrm{c})$,

$$
\begin{aligned}
p^{\mathrm{I}}=254313 & -\frac{000038 \times 300}{135} \\
& =254305 \mathrm{~mm}
\end{aligned}
$$

Correction for dead space

$$
\begin{aligned}
p-p^{\mathrm{I}} & =2543\left[\frac{0133(1+232 \epsilon)(-103 \epsilon)+764(1-799 \epsilon)(-206 \epsilon)}{927(1+232 \epsilon)(1-799 \epsilon)}\right] \\
& =-149 \mathrm{~mm}
\end{aligned}
$$

Whereupon

$$
p=25282 \mathrm{~mm}
$$

Calculation of the temperature $p_{\circ}=76317 \mathrm{~mm}$.

From (3)

$$
\hat{\epsilon}_{0}^{100}=00036623
$$

$$
t=\frac{1}{p_{0}^{t} \epsilon_{0}}[25282(1-0000013)-76317]=-18260^{\circ} \mathrm{C}
$$




\section{The Relation Between the Constant Volume Gas Scale and the Kelvin Thermodynamic Scale}

The international practical scale of temperature is that of the hydrogen constant volume thermometer with initial pressure $\left(0^{\circ} \mathrm{C}\right)$ of one thousand millimeters of mercury ${ }^{3}$ At the time of this definition, hydrogen was the most nearly "perfect" gas known and the deviations of its scale from the absolute thermodynamic scale were supposedly no greater than the experimental error of gas thermometry The scientific definition of temperature 1s contained in the second law of thermodynamics and it becomes a matter of fundamental importance to interpret the temperature indications of the constant volume gas thermometer with the rational thermodynamic scale or Kelvin scale

Consider the thermodynamic relation expressing the dependence of the internal energy, $U$, of a gas upon its volume at constant temperature.

$$
\begin{aligned}
\left(\frac{\partial U}{\partial v}\right)_{T} & =T\left(\frac{\partial p}{\partial T}\right)_{v}-p \\
& =T^{2}\left\{\frac{\partial(p / T)}{\partial T}\right\} .
\end{aligned}
$$

If $(\delta U / \delta v)_{T}=0$ as in the case of the perfect gas, we obtain from (7)

or

$$
\begin{aligned}
& \frac{p}{T}-\frac{p_{\circ}}{T_{\circ}}=0 \text { at constant volume } \\
& T_{\circ}\left(p-p_{\circ}\right)-p_{\circ} t=0 \\
& t=\frac{p-p_{\circ}}{\epsilon p_{\circ}}
\end{aligned}
$$

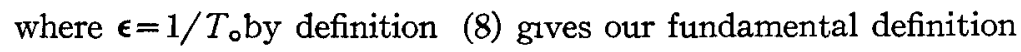
of centigrade temperature in terms of the constant volume " perfect gas" thermometer

For an actual gas $\left(\delta U / \delta_{v}\right)_{T} \neq 0$ and the gas scale temperature is therefore defined by (1), viz :

$$
t=\frac{p-p_{0}}{\epsilon_{0} p_{0}}
$$

3 Comité international des Poids et Mesures, Oct 15, 1887.

4 Lord Kelvin, Math and Phys Papers, Vol. 1, p. 100, 1848. 
Designate the quantity $(\delta U / \delta v)_{T}$ by $\lambda$, where $\lambda$ may be a function of the absolute temperature, designated by $T$ Then in general we have for the constant volume thermometer:

$$
\frac{p}{T}-\frac{p_{0}}{T_{0}}=\int_{T_{\circ}}^{T} \frac{\lambda}{T^{2}} d T
$$

Puttıng, for brevity, $\int_{T_{0}}^{T} \frac{\lambda}{T^{2}} d T=I=\frac{T_{0}\left(p-p_{0}\right)-p_{\circ} t}{T T_{\circ}}$

$$
\text { whence, since } \frac{p-p_{0}}{p_{0} t}=\stackrel{t}{\epsilon_{0}}, \quad \stackrel{t}{\epsilon}_{0}^{t}=\epsilon+\frac{T I}{p_{0} t}
$$

where $\epsilon$ is the expansion coefficient of a perfect gas, or $1 / T_{0}$. Equation (10) would serve to evaluate $t_{0}^{t}$ for any gas, provided there were means of determining $\lambda$, and hence $I \quad \lambda$ has not been successfully measured experimentally

It is to be noted that the temperature given by (1) is the true

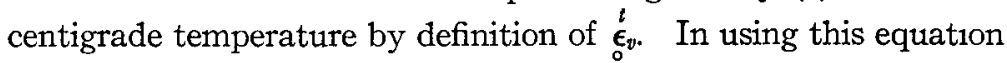
it has been customary to put for $\stackrel{t}{\epsilon}_{0}$ the measured mean pressure coefficient between $0^{\circ} \mathrm{C}$ and $100^{\circ} \mathrm{C}$, namely, ${ }^{100}$. In this case there results.

$$
t_{g}=\frac{p-p_{0}}{\substack{t_{0} \\ 0}}
$$

and

$$
t_{g}-t=t . \frac{\frac{t_{\epsilon}-100}{\sigma_{v}-\epsilon_{0}}}{\substack{100 \\ \epsilon_{v}}}
$$

Obviously, if the pressure is a linear function of the temperature at constant volume, $t_{g}-t=0$, and the temperature given by (11) needs no correction 


\section{A. The Equation of State for Gases}

Much evidence has recently come to hand, that in a gaseous system composed of invariable species of molecule* the pressure at constant volume actually varies linearly with the temperature. Ramsay and Young reached this conclusion from a study of the ether and carbon dioxide isometrics The equation of Van der Waals, moreover, is of this form, and the equation of state deduced by Keyes $^{\mathbf{6 , 7}, \mathbf{8}}$.

$$
p=\frac{R T}{v-\delta}-\frac{A}{(v-l)^{2}}
$$

where $\delta=\beta e^{-\alpha / v}$ for polyatomic gases and $\delta=\beta$ for monatomic gases requires a linear increase of pressure with temperature. The satisfactory agreement of this equation with the experimental data on nitrogen, air argon, hydrogen, helium, carbon dioxide, ammonia, steam, ether, methane, and isopentane make it seem highly probable that it represents the facts well within the experimental error Once given an equation of state it becomes possible, of course, to calculate such quantities as $\stackrel{t}{\epsilon},_{0}, \epsilon_{0}^{t}$, the Joule-Thomson coefficient $\mu, \frac{\partial\left(p_{v}\right)}{\partial p}$, and also the absolute ice point temperature, $T_{0}$ The agreement of the results of such calculations with experiment furnishes additional and critical evidence of the validity of the form of the equation $W_{1}$ th these results the conclusion is reached that the constant volume gas thermometer, operated within the range where the species of molecule is invariable, and where adsorption of the gas upon the walls of the container is not a factor, indicates the absolute thermodynamic temperature without correction

\footnotetext{
* i.e. dissociation or association must not take place within the contemplated range

Nature, 44, pp. 276, 608, 1891 ; also Preston, Theory of Heat (3 ed.), p.460.

6 Keyes, Proc. Nat. Acad. Sci. 3, p. 323, 1917.

7 Phillips, This Jour, 1, p. 42, 1921.

8 Keyes, Jour. Am Soc Refrig. Engrs , 1, 9, 1914.

Keyes, Jour Am. Chem. Soc., 41, 589, 1919.

Keyes, Jour. Am Chem. Soc., 42, 54, 1920.

Keyes, Jour. Am Soc. Refrng. Engrs. 7, 371, 1921.

Keyes, Jour. Am. Chem. Soc , 43, 1452, 1921.

Keyes, This Jour. 1, 89, 1922.
} 
This conclusion can, however, be subjected to direct experimental test, for if there is a thermodynamic correction it must be proportional to the initial pressure of the gas and may be determined by measuring the same temperature at different initial pressures and extrapolating to zero initial pressure. Thus, if the measured temperatures plotted against the initial pressure give a straight line which is not horizontal, it may be concluded there is a thermodynamic correction On the other hand, if it is found that a curved line results, the deviations must be laid in part at least to some source other than an intrinsic property of the gas,

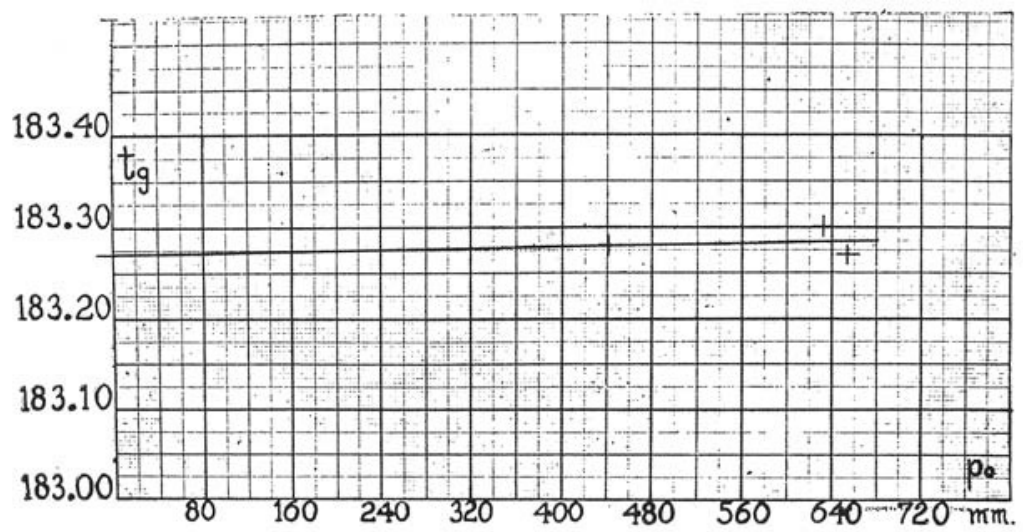

Fig. 1

such as adsorption, or a change in the molecular species of the thermometric gas Measurements of this sort, using nitrogen as the thermometric gas, for which the correction is supposed to be relatively large, were made The comparison temperature was that of liquid air, and the readings were referred to the same actual temperature by means of a multiple thermocouple, sensitive to $0.01^{\circ} \mathrm{C}$, immersed with the gas thermometer The mean of several determinations at each initial pressure has been plotted against the initial pressure in Fig 1 . It will be seen that the mean of determinations at approximately $640 \mathrm{~mm}$ agrees with those

9 F. Henning, Temperaturmessung (F. Vieweg u. Sohn, 1915), p. 67. 
at $440 \mathrm{~mm}$ within the experimental error According to the corrections to the constant volume nitrogen scale calculated by $\mathrm{D}$ Berthelot, ${ }^{10}$ however, the measured temperatures at these two initial pressures should have differed by $012^{\circ}$ In point of fact they are seen to differ by less than $001^{\circ}$

We shall find that the nitrogen thermometer, however, does differ in its indications from those of the hydrogen thermometer at liquid air temperatures by about as much as $06^{\circ} \mathrm{C}$ This deviation is explainable by adsorption of the gas on the walls of its container, or polymenzation of the nitrogen, as will be shown in discussing the direct comparison of the two thermometers

\section{B The Normal Sulfur Boiling Point}

The errors that may be introduced by surface effects of the container are impressively illustrated in the discrepancies in the measurements of the pressure and volume coefficients of gases by various observers For illustration, consider the careful and representative measurements of the boiling point of sulfur by Holborn and Henning ${ }^{11}$ and by Eumorfopoulos ${ }^{12}$ The latter used a Callendar constant-pressure nitrogen thermometer with quartz bulbs The nitrogen was prepared and the instrument loaded in such a way as to insure the purity of the gas It was found, that after pumping out this loadıng and evacuating at $500^{\circ} \mathrm{C}$, the coefficient of expansion of a new loading was appreciably lower than that of the first Several repetitions of this process finally reduced the measured coefficient to a constant value A similar effect was observed in other sets of experiments In each case, the final value of the coefficient agrees excellently with that calculated by means of the nitrogen equation of state of Keyes (12) These results are shown in the following table Between successive observations the bulb was heated to $500^{\circ} \mathrm{C}$ and thoroughly exhausted Eumorfopoulos chose the final values of the volume coefficient of each series in the calculation of the temperature of boiling sulfur.

10Berthelot, Trav, et Mem. Bur. Int. 13, 1907.

11 Holborn and Henning, Ann. d Phys. 35, p 761, 1911.

12Eumorfopoulos, Proc. Roy Soc 90, A, p. 189, 1914. 
TABLE I

\begin{tabular}{l|c|c|c|c}
\hline \hline & $\begin{array}{c}\text { Initual } \\
\text { Pressure } \\
m m\end{array}$ & $\begin{array}{c}100 \\
\epsilon_{p} \times 10^{7} \text { Obs }\end{array}$ & $\begin{array}{c}100 \\
\epsilon_{p} \times 10^{7} \text { Calc } \\
0\end{array}$ & $\begin{array}{c}\text { Obs -Calc } \\
\times 10^{7}\end{array}$ \\
\hline First & 760 & 36714 & 36695 & 19 \\
Series & 763 & 36702 & 36696 & 6 \\
& 784 & 36702 & 36698 & 4 \\
Second & 756 & 36728 & 36695 & 33 \\
Series & 756 & 36704 & 36695 & 9 \\
& 757 & 36701 & 36995 & 6 \\
\hline
\end{tabular}

The foregoing results clearly indicate the necessity of repeated loading and exhausting at high temperature, and the unreliability of measurements where this precaution has not been taken The following table gives a comparison of the finally accepted coefficrents at the varous initial pressures used by Eumorfopoulos with those calculated from the equation of state

TABLE II

\begin{tabular}{c|c|c|c}
\hline $\begin{array}{c}\text { Invtral Pressure } \\
m m\end{array}$ & $\begin{array}{l}\text { Obs } \\
\times 10^{7}\end{array}$ & $\begin{array}{l}\text { Calc } \\
\times 10^{7}\end{array}$ & $\begin{array}{c}\text { Obs - Calc } \\
\times 10^{7}\end{array}$ \\
\hline 792 & 36701 & 36699 & 2 \\
784 & 36702 & 36698 & 4 \\
757 & 36699 & 36695 & 4 \\
415 & 36659 & 36657 & 2 \\
395 & 36656 & 36655 & 1 \\
\hline
\end{tabular}

By extrapolation of the experimental values to zero pressure, Eumorfopoulos found the coefficient of the perfect gas to be 00036613 , giving the ice point on the thermodynamic scale as $27313^{\circ} \mathrm{C}$, which is in almost exact agreement with the value calculated by Keyes ${ }^{13}$ several years ago from (12), and also obtained by Buckingham ${ }^{14}$ from a study of the avallable Joule-Thomson data

The normal sulfur boiling point was measured at these different. initial pressures and the values extrapolated to zero pressure to obtain the N B P on the thermodynamic scale Eumorfopoulos found this to be $44461^{\circ} \mathrm{C}$ If we take the various actually observed

13Keyes, Jour Am Chem Soc, 42, 54 (1920)

14.Buckingham, Bull. Bur. Stand, 3, 237 (1907) 
boiling points and apply to each the thermodynamic correction for the constant pressure nitrogen scale calculated from the equation of state (12) we find the following values

TABLE III

\begin{tabular}{c|c|c}
\hline \hline $\begin{array}{c}\text { Intial Pressure } \\
m m\end{array}$ & Temp Obs & $\begin{array}{c}\text { Normal S B P } \\
\text { Corr. }\end{array}$ \\
\hline 792 & 44413 & 44453 \\
784 & 44414 & 44453 \\
757 & 44413 & 44451 \\
415 & 44436 & 44457 \\
& 44439 & 44459 \\
\hline
\end{tabular}

Consider the work of Holborn and Henning on this same fixed point They employed platinum resistance thermometers which had been directly compared with the constant volume gas thermometers of helium, hydrogen and nitrogen The value obtained from the comparison with helium and hydrogen was $44451^{\circ} \mathrm{C}$ and considered final, since the thermodynamic correction to these scales was assumed less than the expenmental error From the comparison with the nitrogen gas thermometer, however, they found the value $44443 \mathrm{C}$ To this value they applied the Berthelot correction, thus bringing it up to $44459^{\circ} \mathrm{C}$ The application of the correction evidently does not diminish the discrepancy between the two values, but merely changes its sign A study of their results brings out, nevertheless, certain inconsistencies in the measurements of the pressure coefficients of nitrogen Thus, the mean of the nitrogen coefficients measured in a quartz contanner at $621 \mathrm{~mm}$ was 00036684 , whereas two series in Jena glass gave 00036704 (at $631 \mathrm{~mm}$ ), and 00036710 (at $621 \mathrm{~mm}$ ) For helium and hydrogen, the measured coefficients were 00036618 (at 612 $\mathrm{mm}$ ), and 00036625 (at $623 \mathrm{~mm}$ ) respectively These coefficients seem too large - for helium and hydrogen only very slightly ( 1 part in 10,000), for nitrogen decidedly ( 1 part in 3060 ) - on comparison with the values computed from (12) If we assume the calculated values correct, the gas thermometer temperatures become $44455^{\circ} \mathrm{C}$ on the helium and hydrogen scales, and $44457^{\circ} \mathrm{C}$ 
on the nitrogen scale Using, therefore, the gas expansion coeffcients calculated from the equation of state of Keyes, and making no correction to the constant volume thermometer while using the corrections for the constant pressure nitrogen scale as computed by Keyes, there results the following excellent agreement in the sulfur N B P.

TABLE IV

Normal Sulfur Borling Point

\begin{tabular}{|c|c|c|}
\hline Observer & $\begin{array}{cc}\text { Gas Thermometer } \\
\text { Gas } & \text { Constant }\end{array}$ & $t$ \\
\hline $\begin{array}{l}\text { Holborn and Henning,1911 } \\
\text { Holborn and Henning,1911 } \\
\text { Eumorfopoulos, 1914 }\end{array}$ & $\begin{array}{l}\text { Volume } \\
\text { Volume } \\
\text { Pressure }\end{array}$ & $\begin{array}{l}44455 \\
44457 \\
44455\end{array}$ \\
\hline
\end{tabular}

$C$ The Usual Corrections to the Constant Volume Thermometer

The disctission of this subject would be incomplete without a critical review of the methods which have been used by RoseInnes ${ }^{15}$, Berthelot ${ }^{16}$, Buckingham ${ }^{17}$, and Callendar ${ }^{18}$ in computing corrections for constant pressure and constant volume gas thermometers *

Rose-Innes assumed that the Joule-Thomson data for hydrogen and nitrogen could be represented by

$$
\mu C_{p}^{* *}=a_{\circ}+\frac{a_{1}}{T}+\frac{a_{2}}{T_{2}}
$$

From this an equation of state

$$
p v=R T-p\left[a_{\circ}+\frac{a_{1}}{2 T}+\frac{a_{2}}{3 T^{2}}\right]
$$

15 Rose-Innes, Phil Mag (6), 2, p 130, 1901 and Ph1 Mag. (6), 15, p. 301, 1908.

16 Berthelot, Mem Trav Bur Int, 13, 1907

17 Buckıngham, Bull Bur. Stan , 3, 237, 1907.

18 Callendar, Phil. Mag (6), б, p 48, 1903 p. 72

For a resumé of the various methods see Henning, Temperaturmessung, ${ }^{* *} \mu C_{p}$ is defined from the thermodynamic equation for the Joule-Thomson effect, namely,

$$
\mu C_{p}=\frac{\partial T}{\partial p} C_{p}=T\left(\frac{\partial v}{\partial T}\right)_{p}-v
$$


is derived subject to the condition that

$$
\left\{\frac{\partial(p v)}{\partial p}\right\}=-\left[a_{\circ}+\frac{a_{1}}{2 T}+\frac{a_{2}}{3 T^{2}}\right]
$$

It follows then that the correction to the constant volume scale is

$$
\left[t_{g}\right]_{v}-t=\frac{a_{2}}{3 v} \frac{\left(t-t_{0}\right)\left(t-t_{1}\right)}{t t_{\circ} t_{1}}
$$

and the correction to the constant pressure scale is

$$
\left[t_{g}\right]_{p}-t=\frac{\left(t-t_{\mathrm{o}}\right)\left(t-t_{1}\right)}{t t_{1}}\left\{\frac{a_{1}}{2 V_{\mathrm{o}}}+\frac{a_{2}}{3 V_{\mathrm{o}}}\left(\frac{1}{t}+\frac{1}{t_{\mathrm{o}}}+\frac{1}{t_{1}}\right)\right\}
$$

where the subscripts 0 and 1 refer to the freezing and bolling points of water The constants $a_{0}, a_{1}, a_{2}$ were evaluated from JouleThomson data and the compressibility data of Amagat and of Chappu1s

Berthelot, on the assumption that the isotherms $(p v, p)$ are straight lines within the region of gas thermometer pressure, found the following correction equations:

$$
\begin{aligned}
& {\left[t_{g}\right]_{v}-t=p_{\circ}\left[273(t-100)\left\{\frac{\partial(p v)}{\partial p}\right\}_{0}-373 t\left\{\frac{\partial(p v)}{\partial p}\right\}_{100}\right.}\left.+(273+t)\left\{\frac{\partial(p v)}{\partial p}\right\}_{t}\right] \\
& {\left[t_{g}\right]_{p}-t=273 p \circ\left[(t-100)\left\{\frac{\partial(p v)}{\partial p}\right\}_{\circ}-t\left\{\frac{\partial(p v)}{\partial p}\right\}_{100}+100\left\{\frac{\partial(p v)}{\partial p}\right\}\right] }
\end{aligned}
$$

Values of $\frac{\partial(p v)}{\partial p}$ were taken from various sources, and the range extended by means of the law of corresponding states

Buckingham extended the range of Joule-Thomson coefficients by means of the law of corresponding states, and then calculated the correction to the constant pressure thermometer from the relation 


$$
t-\left[t_{g}\right]_{p}=\left[t_{g}\right]_{p} \frac{T_{\circ}-T^{\prime}}{T_{1}}-T^{\prime} \frac{p_{0}}{R} \int_{T_{\circ}^{\prime}}^{T^{\prime}} \frac{\mu^{\prime} C_{p} d T^{\prime}}{T^{\prime}}
$$

The corrections* to the constant volume scale were derived from a combination of the above with isothermal data, according to the relation

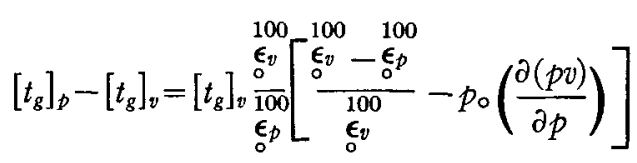

To obtain $\left\{\frac{\partial(p v)}{\partial p}\right\}_{t}$ Buckingham used the equation of Berthelot: on the other hand $\left\{\frac{\partial(p v)}{\partial p}\right\}_{T}=b-\frac{a}{R T^{2}}$

Callendar, on the other hand, based his calculations upon an equation of state of the Clausius-Nerthelot form

$$
p v=R T+p\left(b-\frac{a}{R T^{n}}\right)
$$

where $n$ was taken as a characternstic constant of the gas, 05 for monatomic, 15 for diatomic, and 23 for polyatomic gases

The two outstanding features of the four investigations outlined above are: (1) the assumption of a $\left(\frac{\partial(p v)}{\partial p}\right)_{T}$ function at ordinary pressures in inverse powers of $T$, and (2) the assumption of the validity of the law of corresponding states in extending the range of values of $\left(\frac{\partial(p v)}{\dot{\sigma} p}\right)_{T}$ and $\mu$

To determine the correctness of the first of these assumptions it is simply necessary to plot experimental values of $\left(\frac{\partial(p v)}{\partial p}\right)_{T}$ against $1 / T$ Th1s has been done ${ }^{19}$ for hydrogen, nitrogen, and carbon droxide from the results of Chappuis, Rayleigh, Leduc,

19 Keyes, J. Math. Phys. M. I T., 1, 89, 1922.

* The prime refers to quantities measured on the gas scale. 
Leduc and Sacerdot, Schalkwijk, and Jaquerod and Scheurer In each case a straight line 1 s the most representative one that can be drawn Thus the form of the function at the pressures used in gas thermometry is

$$
\left\{\frac{\partial(p v)}{\partial p}\right\}_{T}=a+\frac{b}{T}
$$

From this it follows

$$
p v=\left(a+\frac{b}{T}\right) p+f(T)
$$

and, since at very low pressures $p v=f(T)=R T$, we have

$$
p v=R T+p\left(a+\frac{b}{T}\right)
$$

In the second term $p$ may be replaced by $R T / v$, giving

$$
\begin{aligned}
p v & =R T\left(1+\frac{a}{v}\right)+\frac{R b}{v} \\
& =\frac{R T v}{v-a}+\frac{R b}{v}
\end{aligned}
$$

so that

$$
p=\frac{R T}{v-a}+\frac{R b}{v^{2}}
$$

an equation of the type of (12) at low pressures and showing the pressure to be a linear function of the temperature at constant volume

Assumption (2), involving the use of the law of corresponding states, is questionable It has been shown to be invalid on the basis of the experimental data The equation of state of Keyes indicates that the law is in general only true for monatomic substances and then with certain modifications over the usual form of statement In the latter case, the values of the critical constants to be taken are not those experimentally measured at the true critical point, but rather the values at the critical point the substance would have if it conformed to its equation of state, right up to the point of condensation This, in general, is not the case, owing to association of the molecules as the specific volume approaches that of the liquid 
D. Analysis of the Isothermals and Isometrics of Hydrogen Finally, mention should be made of the investigation of Kamerlingh Onnes and $\mathrm{Braak}^{20}$ in which corrections for the constant

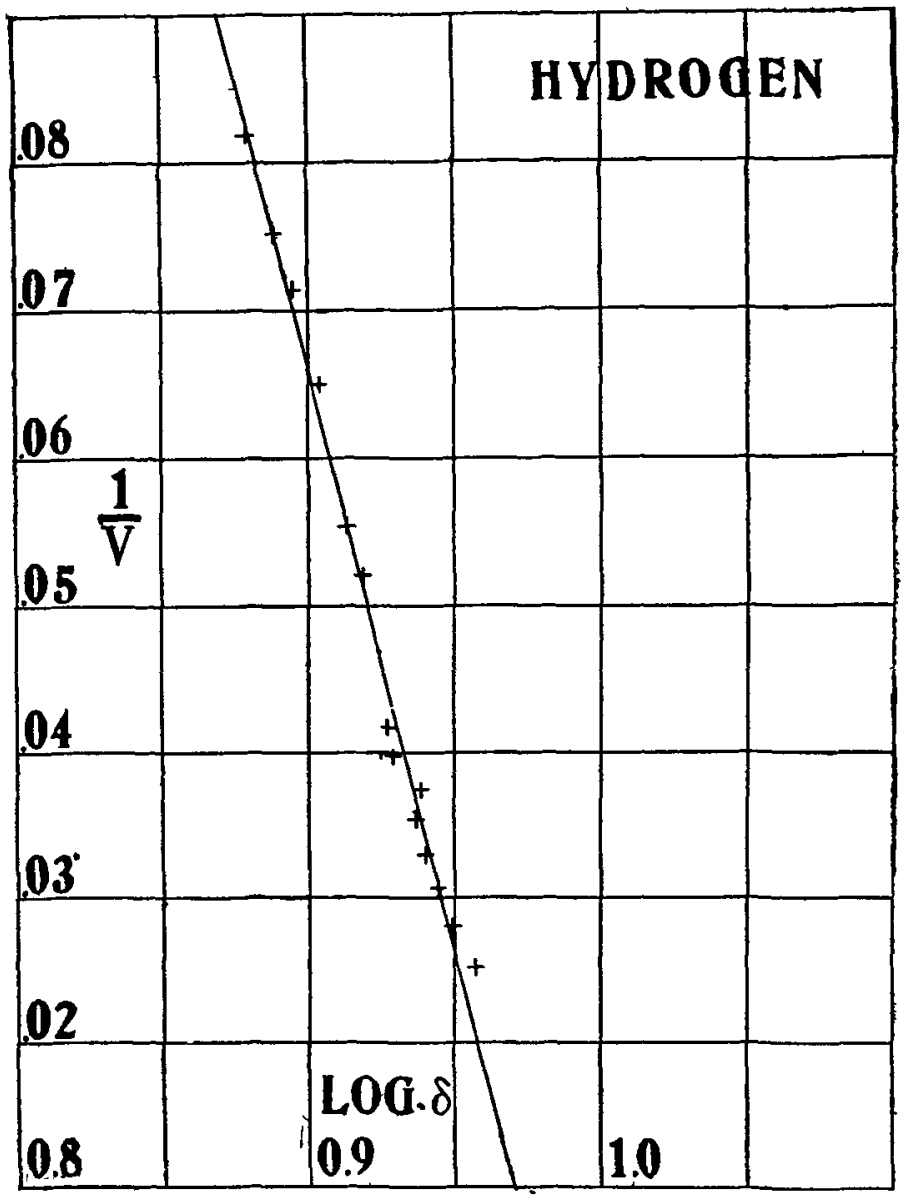

Fig. 2

volume hydrogen thermometer were determined from direct observations of the isotherms of hydrogen The isotherms were 20 Onnes and Braak, Le1den Comm. Nos. 97 (1906); 99a, 100a (1907). 
here represented as a function of the inverse volume, namely,

$$
p v_{A}=A_{A}+\frac{B_{A}}{v_{A}}+\frac{C_{A}}{v^{2} A}+\frac{D_{A}}{v^{4}{ }_{A}}+\frac{E_{A}}{v^{6}{ }_{A}}+\frac{F_{A}}{v^{8}}+\ldots .
$$

where the subscript $A$ denotes values on the absolute scale. Since the actual measurements are referred to the hydrogen constant volume scale, the coefficients first calculated for this expression are an approximation They can be used to determine provisional corrections to the temperature scale and then, with these, better values for the constants can be found This method of successive approximations is applied until no change results from a repetition of the process.

In general the number of observations on any one isotherm were no greater than the number of "viral coefficients" chosen to represent it Complete accordance between observed and calculated values can thus be obtained; but it must be remarked that the final equation embodies whatever errors there may have been in the measurements themselves It may not happen, for example, that such an equation would be the best representative line that could be drawn through the data

The constants for hydrogen in the Keyes equation of state were evaluated from data of Amagat and of Onnes and Braak The Amagat data covered the range from $0^{\circ}$ to $200^{\circ}$ and from them the $\delta$ function could be determined The relative magnitude of the $\frac{A}{(v-l)^{2}}$ term is so small here, however, that the constants $A$ and $l$ could not be found at all accurately For this purpose, recourse was had to measurements at low temperatures, using the value of $\delta$ previously determined In Fig $2, \log \delta$ is plotted against $1 / v$ for the Amagat data The points give a straight line, the equation of which is $\log \delta=\log \beta-a / v$ With the $\delta$ function determined in this way, we may calculate $\phi,\left(\frac{A}{(v-l)^{2}}\right)$, from the data of the observers listed in Fig 3 and plot the volume against $\frac{1}{\sqrt{\phi}}$ as is 
here done. The best representative line is again straight, and from it the constants $A$ and $l$ are determinable The inconsistency of the various measurements at low temperatures is apparent from the irregularity of the deviations The equation of state for hydrogen thus takes the form

where

$$
p=\frac{4072 T}{v-\delta}-\frac{39102}{(v-1183)^{2}}
$$

in gram, atm, c.c units.

$$
\log _{10} \delta=09831-\frac{126}{v}
$$

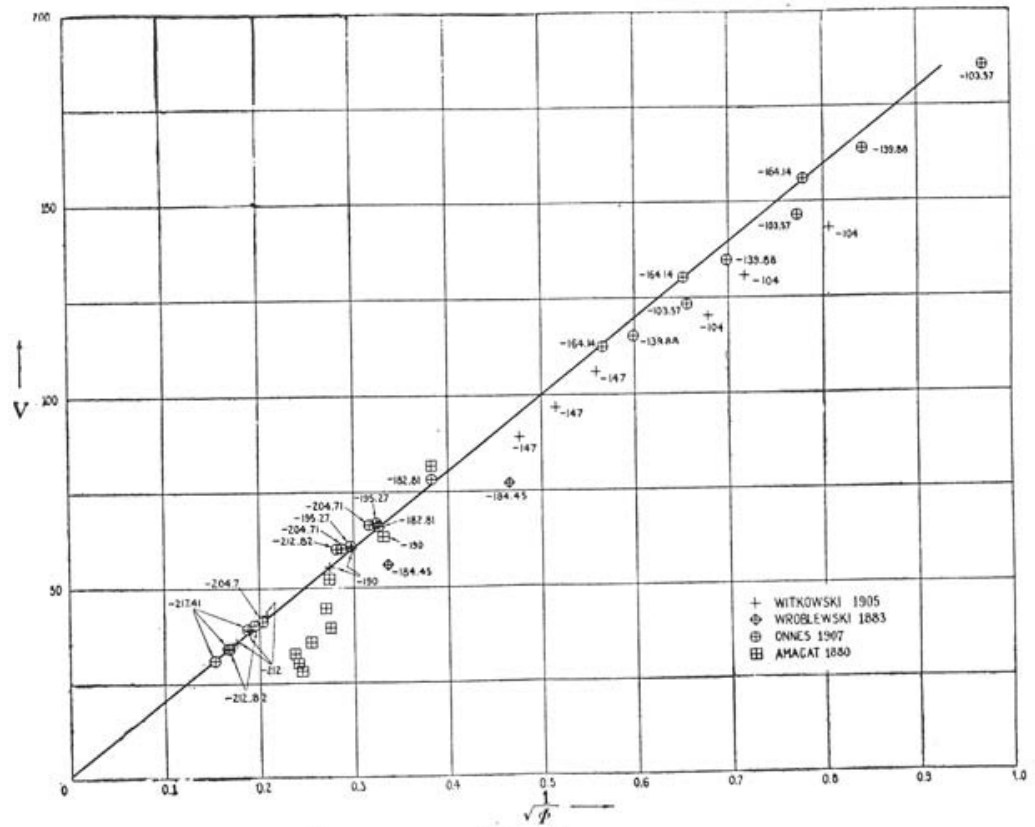

Fig. 3

Tables $\mathrm{V}$ and VI give a comparison of the pressures calculated from this equation of state with the observed pressures of Onnes and Braak, ${ }^{21}$ Onnes, Crommelin and Miss Smid, ${ }^{22}$ and Witkowski. $^{23}$ While the deviations are not large, seldom one per cent

21 Onnes and Braak, Le1den Comm., 100b (1907).

22 Onnes, Crommelin and Miss Smid, Leiden Comm., 146b (1915).

23 Witkowski, Krak. Anz. 305, 1905. 


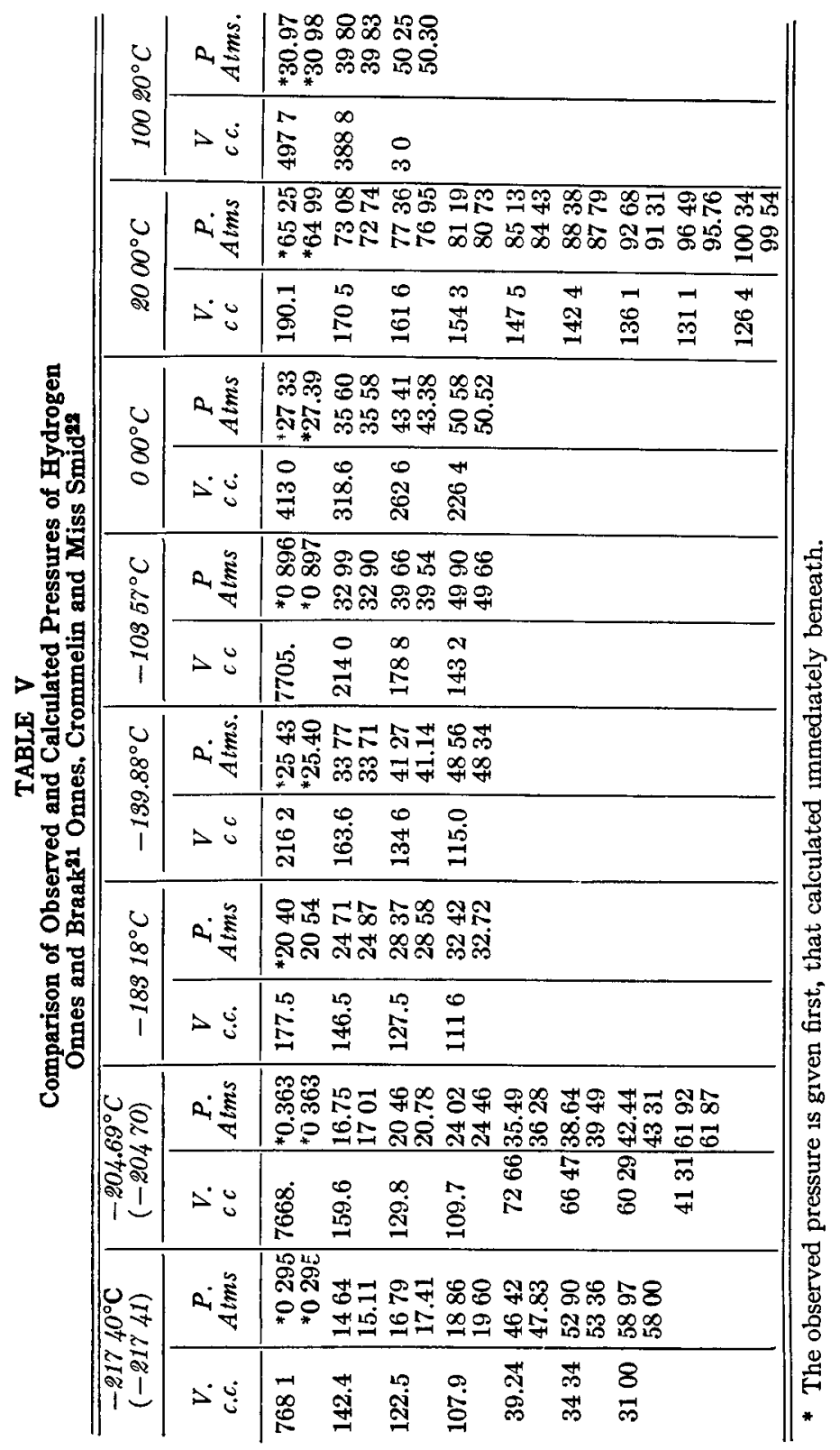




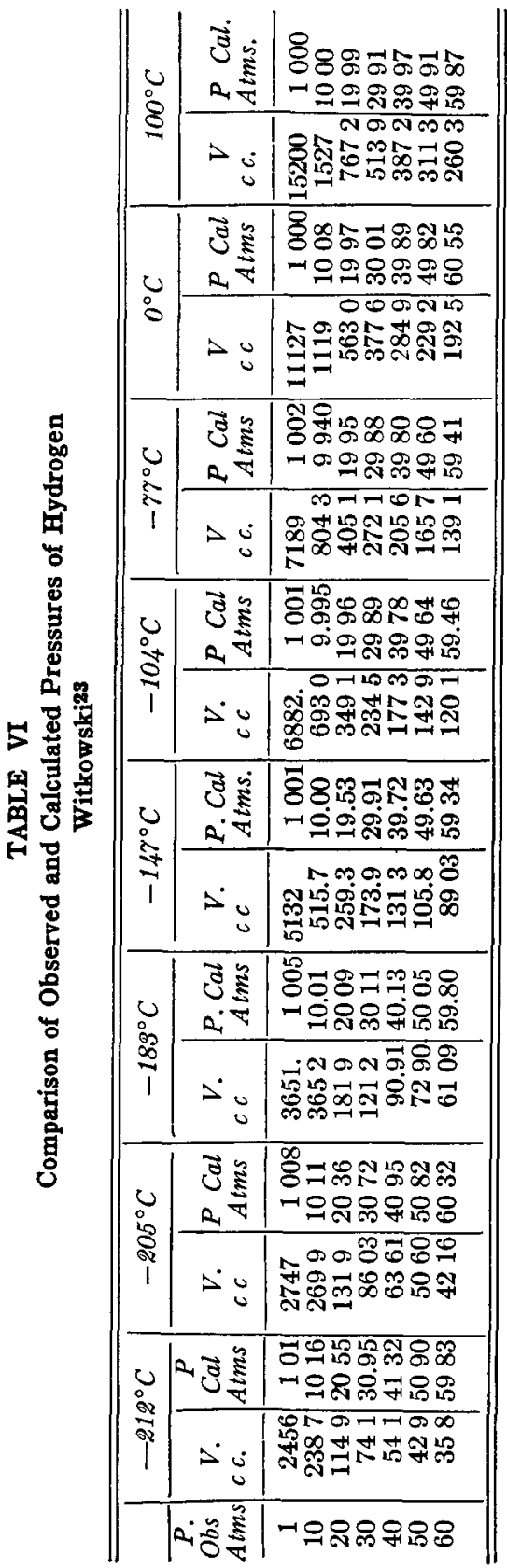


the agreement is not as good as might be wished In Fig 4, the deviations of the calculated from the observed pressures are plotted for the Leiden data and those of Witkowsk1 The former are represented by dotted, and the latter by solid lines For isotherms from $+100^{\circ}$ to $-140^{\circ}$ the deviation increases fairly regularly, the calculated value being too small, and amounting to about one-half of one per cent at 60 atms At lower temperatures the

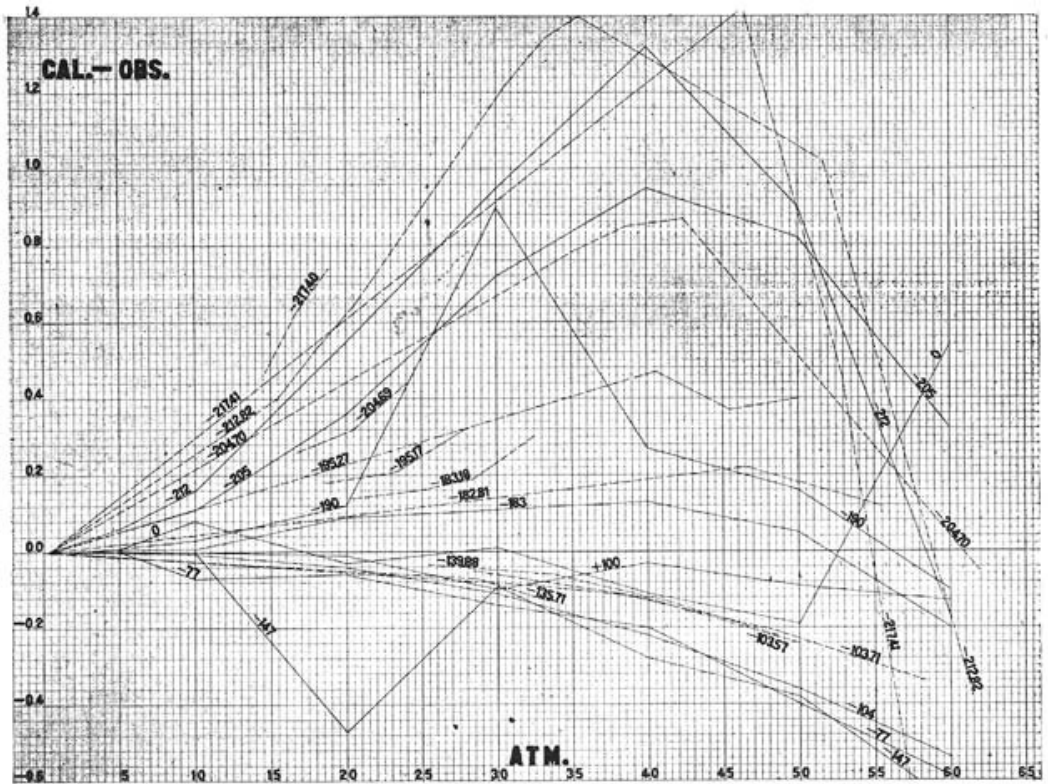

Fig 4

deviations have the opposite sign and increase to a maximum (ca $2 \%$ ) at about $40 \mathrm{atms}$ and then rapidly decrease The plot reveals much greater discrepancies in the data than were suspected by the observers For example, at 205 atms the deviation of the $20469^{\circ}$ isotherm differs from that of the $20470^{\circ}$ isotherm by $016 \mathrm{~atm}$ Since these temperatures are the same within the limits of experiment, it follows that the observed pressures, at this particular point, differ by more than 05 per cent Several other 
cases will be found as striking The deviations are too inconsistent to surely indicate a fault in the values calculated by means of the equation of state This inconsistency is further brought out in a comparison of calculated with observed values at extremely low temperatures Table VII contains such a comparison, based on

TABLE VII

Comparison of Observed and Calculated Pressures of Hydrogen Onnes and de Haas 24

\begin{tabular}{|c|c|c|c|c|c|}
\hline \multicolumn{2}{|c|}{$-25726^{\circ} \mathrm{C}$} & \multicolumn{2}{|c|}{$-25546^{\circ} \mathrm{C}$} & \multicolumn{2}{|c|}{$-25263^{\circ} \mathrm{C}$} \\
\hline $\begin{array}{c}V \\
c c .\end{array}$ & $\begin{array}{c}P \\
\text { Atms }\end{array}$ & $\begin{array}{l}V \\
c c\end{array}$ & $\begin{array}{c}P \\
\text { Atms. }\end{array}$ & $\begin{array}{c}V \\
c c\end{array}$ & $\underset{\text { Atms }}{P}$ \\
\hline $\begin{array}{l}9603 \\
4829\end{array}$ & $\begin{array}{ll}0 & 06698^{*} \\
0 & 06698^{*} \\
0 & 13153 \\
0 & 13250\end{array}$ & $\begin{array}{l}6514 \\
3415 \\
2520 \\
2225 \\
2223\end{array}$ & $\begin{array}{l}010964^{*} \\
0 \quad 10976^{*} \\
020672 \\
020806 \\
027759 \\
028065 \\
0 \quad 31294 \\
031707 \\
031318 \\
031730\end{array}$ & $\begin{array}{l}2338 \\
1315\end{array}$ & $\begin{array}{l}034786^{*} \\
036884^{*} \\
0.60358 \\
064848\end{array}$ \\
\hline
\end{tabular}

the data of Onnes and de Haas Evidently, at temperatures very nearly the same and at the same volumes, the deviations of the calculated from the observed pressures in the vanous series are very different Moreover, at such large volumes it seems improbable that the deviation from the perfect gas law is as great as the measurements indicate

Another, and more direct, method is avalable for analyzing the data on hydrogen This consists in determining the isometrics and for this purpose the pressures $\dagger$ have been calculated for a number of fixed volumes from the 1sothermal equations of Onnes The isometrics so calculated are presented in Table VIII and Fig 5 In each case a straight line seems best to represent the data If we denote the equation of an isometric by

$$
p=\psi T-\phi
$$

the values of $\psi$ and $\phi$ obtained from the lines of $\mathrm{F}_{1 \mathrm{~g}} 5$ are given in Table IX

* The observed pressure is given first, that calculated immediately beneath. $\dagger$ Pressures in atmospheres

24 Onnes and de Haas, Leiden Comm , 127c, 1912 
KEYES, TOWNSHEND AND YOUNG

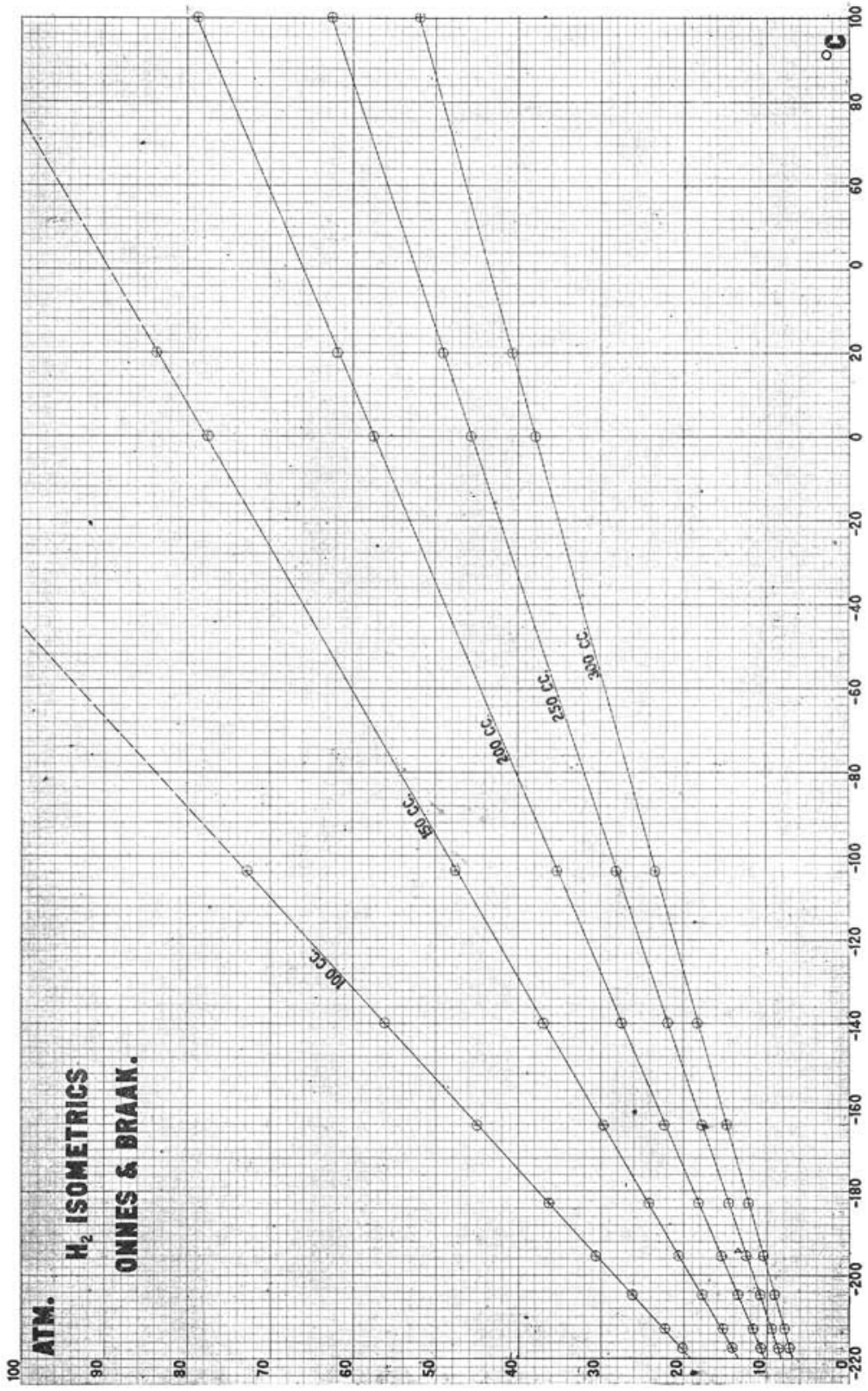


TABLE VIII

$\mathrm{H}_{2}$ Isometrics. Onnes and Braak,21 Onnes, Crommelın, and Miss Smıd ${ }^{22}$

\begin{tabular}{c|c|c|c|c|r}
\hline \hline$t^{\circ} \mathrm{C}$ & $100 c c$ & $150 c c$ & $200 c c$ & $250 c c$ & $300 c c$ \\
\hline-21741 & 20169 & 14216 & $\mathbf{1 0} 659$ & 8631 & 7.252 \\
-21282 & 22324 & 15309 & $\mathbf{1 1} 663$ & 9432 & 7906 \\
-20470 & 26212 & 17776 & $\mathbf{1 3} 465$ & $\mathbf{1 0} 841$ & 9074 \\
-19527 & 30622 & 20588 & $\mathbf{1 5 5 2 6}$ & $\mathbf{1 2 4 6 6}$ & 10415 \\
-18281 & 36329 & 24235 & $\mathbf{1 8} 205$ & $\mathbf{1 4 5 8 5}$ & 12167 \\
-16414 & 45032 & 29744 & 22275 & $\mathbf{1 7} 805$ & 14.818 \\
-13988 & 56179 & 36933 & 27531 & 21949 & 18251 \\
-10357 & 72767 & 47561 & 35348 & 28131 & 23363 \\
000 & & 77544 & $\mathbf{5 7 4 7 1}$ & 45657 & 37873 \\
2000 & & 83662 & $\mathbf{6 1 . 8 9 6}$ & 49127 & 40730 \\
10020 & & & 78743 & 62537 & 57863 \\
\hline \hline
\end{tabular}

Fig 6a exhibits the deviations of the observed pressures from those calculated from the constants of the isometric equations presented in Table IX It w1ll be seen that the most representative line has been chosen in each case The conclusion that the pressure is a linear function of the temperature at constant volume is

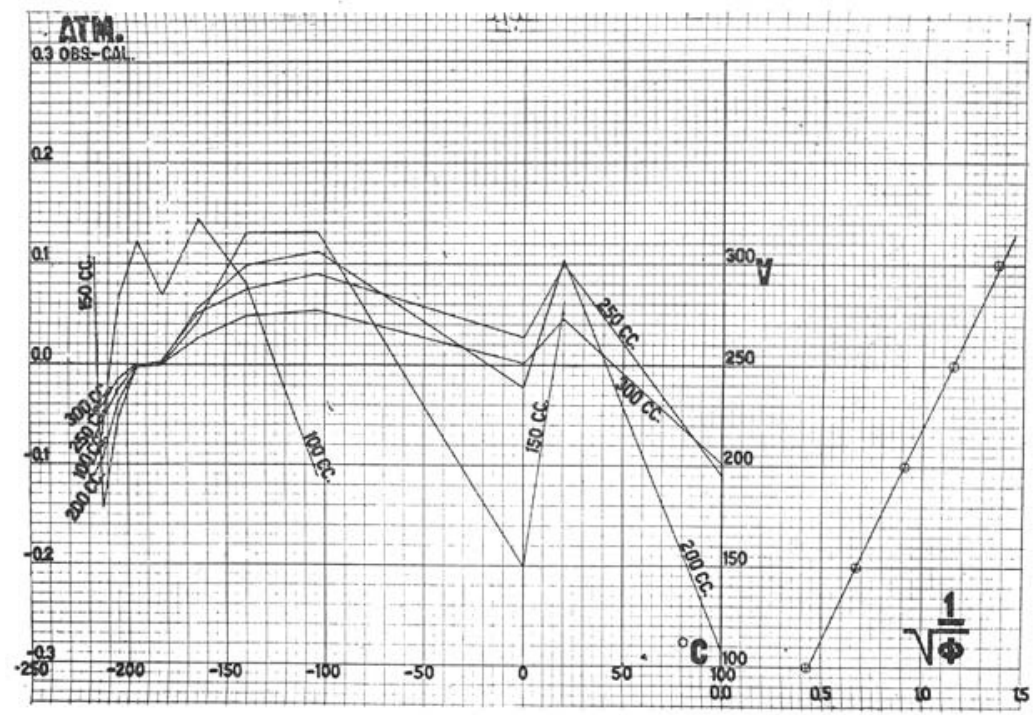

Fig $6 a$

Fig. 6b 
TABLE IX

Constants of the Isometrics of Hydrogen

\begin{tabular}{|c|c|c|c|c|c|c|c|c|c|}
\hline \multicolumn{2}{|c|}{$100 c c$} & \multicolumn{2}{|c|}{$150 \mathrm{cc}$} & \multicolumn{2}{|c|}{$200 \mathrm{cc}$} & \multicolumn{2}{|c|}{$250 \mathrm{cc}$} & \multicolumn{2}{|c|}{$300 c c$} \\
\hline $\begin{array}{c}\boldsymbol{\Psi} \\
046213\end{array}$ & $\begin{array}{|cc|}\mathbf{9} \\
5 & 480\end{array}$ & \begin{tabular}{|c|}
$\Psi$ \\
029270
\end{tabular} & $\mid \begin{array}{c}\Phi \\
2200\end{array}$ & \begin{tabular}{|c|}
$\boldsymbol{\Psi}$ \\
021491
\end{tabular} & $\begin{array}{c}\Phi \\
1205\end{array}$ & \begin{tabular}{cc|} 
\\
0 & 16983
\end{tabular} & $\begin{array}{c}\Phi \\
0.756\end{array}$ & $\left|\begin{array}{cc|}\Psi \\
0 & 14061\end{array}\right|$ & $\begin{array}{c}\stackrel{\Phi}{5} \\
0533\end{array}$ \\
\hline
\end{tabular}

consequently at least not disproved, but supported, as far as the accuracy of the data are concerned It thus becomes difficult to perceive how corrections to the constant volume hydrogen thermometer, deduced from the virial equation based on the same data, can represent a true fact of nature

The constants of the equation of state can be found from the above isometrics for

$$
\frac{R}{v-\delta}=\psi
$$

and

$$
\frac{A}{(v-l)^{2}}=\phi
$$

'The values of $\delta$ derived from the above 1sometrics are given below, compared with the corresponding values of $\delta$ calculated from the equation of state (12a) The variation of $\delta$ is too small to be

TABLE X

Values of $\delta$

\begin{tabular}{l|r|r|r|r|r}
\hline & $100 c c$ & $150 c c$ & $200 c c$ & $250 c . c$. & $800 c c$ \\
\cline { 2 - 4 } & $\begin{array}{r}\mathbf{1 1 8 8} \\
\mathbf{9} 34\end{array}$ & $\begin{array}{r}1088 \\
\mathbf{9 3 4}\end{array}$ & $\begin{array}{r}1052 \\
\mathbf{9} 48\end{array}$ & $\begin{array}{r}1019 \\
\mathbf{9 5 1}\end{array}$ & $\begin{array}{r}1039 \\
\mathbf{9 5 3}\end{array}$ \\
\hline
\end{tabular}

detected within the limits of precision of the measurements, while the discrepancy between the two sets of values corresponds to an error in the volume of about 05 per cent, which is possible in view of discrepancies already indicated

The volume plotted against $\frac{1}{\sqrt{\phi}}$ should give a straight line, 
from the constants of which $A$ and $l$ can be determined This plot is represented in Fig $6 \mathrm{~b}$ The values of $A$ and $l$ from the line there drawn are

$$
A=43600 \quad l=102
$$

Based entirely upon the Leiden data, the equation of state for hydrogen becomes

$$
p=\frac{4072 T}{v-105}-\frac{43600}{(v-102)^{2}}
$$

These constants, it is believed, may not be as reliable as those previously accepted for hydrogen The coefficients of expansion and pressure increase of the gas will not, however, be appreciably altered if calculated with the new constants; but the corrections to the constant pressure hydrogen thermometer will differ from those computed by Buckingham from the Joule-Thomson data The equation of state for hydrogen cannot be considered definitely established, but unt1 more accurate data are avallable, equation (12a), given on page 263, can be regarded as best representing the facts

A critical test of the validity of form of the equation of state, (12a), as well as of its constants, is obtained by calculating the Joule-Thomson coefficients of hydrogen and the inversion temperatures of the Joule-Thomson effect These can then be compared with the values calculated by J P Dalton ${ }^{25}$ from the hydrogen virial coefficients of Onnes

The Joule-Thomson coefficient is defined by the equation

$$
\mu=\frac{T\left(\frac{\partial v}{\partial T}\right)_{p}-v}{C_{p}}
$$

while from the equation of state

$$
\left(\frac{\partial v}{\partial T}\right)_{p}=\frac{(v-\delta)}{T}\left[\frac{1}{1-\frac{2 A}{R T(v-\delta)^{2}}-\frac{a \delta}{v^{2}}}\right]
$$

25 Dalton, Le1den Comm., 109a (1909). 
also

$$
\left(\frac{\partial p}{\partial T}\right)_{v}=\frac{R}{v-\delta}
$$

and

$$
C p=C v+T\left(\frac{\partial p}{\partial T}\right)_{v}\left(\frac{\partial v}{\partial T}\right)_{p}=C_{v}+R\left[\frac{1}{1-\frac{2 A}{R T} \frac{(v-\delta)^{2}}{(v-l)^{3}}-\frac{a \delta}{v^{2}}}\right]
$$

and finally

$$
\mu=\frac{\frac{2 A}{R T} \frac{v(v-\delta)^{2}}{(v-l)^{3}}-\delta\left(1-\frac{a}{v}\right)}{C v\left[1-\frac{2 A}{R T} \frac{(v-\delta)^{2}}{(v-l)^{3}}-\frac{a \delta}{v^{2}}\right]+R}
$$

For values of $\mu$ at low pressures (13) reduced to

$$
\mu=\frac{2 A}{C_{p} R T}-\frac{\beta}{C_{p}}
$$

The inversion temperature, corresponding at $\mu=0$

$$
T_{3}=\frac{\frac{2 A}{R} \quad \frac{v(v-\delta)^{2}}{(v-l)^{3}}}{\delta(1-a / v)}
$$

\begin{tabular}{|c|c|c|}
\hline${ }^{T} \mathrm{C}$ & $\begin{array}{l}\mu \text { from }[18 a] \\
{ }^{\circ} \mathrm{C} \text { per } \mathrm{Atm} .\end{array}$ & $\begin{array}{l}\mu, \text { Dalton }{ }^{25} \\
{ }^{\circ} C \text { per Atm. }\end{array}$ \\
\hline $\begin{array}{l}-215 \\
-186 \\
-157 \\
-128 \\
-99 \\
-845 \\
-70 \\
-41 \\
-12 \\
+17\end{array}$ & $\begin{array}{l}+0167 \\
+0.088 \\
+0.049 \\
+0.026 \\
+0.010 \\
+0004 \\
-0001 \\
-0.010 \\
-0016 \\
-0021\end{array}$ & $\begin{array}{r}+0.291 \\
+0141 \\
+0.073 \\
+0.037 \\
+0.015 \\
+0006 \\
-0001 \\
-0011 \\
-0019 \\
-0026\end{array}$ \\
\hline
\end{tabular}

TABLE XI

Joule-Thomson Coefficient for Hydrogen at 1 Atm.

TABLE XII

Inversion Temperature of Joule-Thomson Effect for Hydrogen

\begin{tabular}{c|c|c}
\hline Pressure Atms & $T_{v}$, from $[14]{ }^{\circ} \mathrm{C}$ & $T_{v}$, Dalton ${ }^{25}{ }^{\circ} \mathrm{C}$ \\
\hline 1 & -73.2 & -726 \\
10 & -759 & -74.1 \\
20 & -783 & -75.8 \\
50 & -85.7 & -81.9 \\
100 & -99.0 & -917 \\
\hline
\end{tabular}




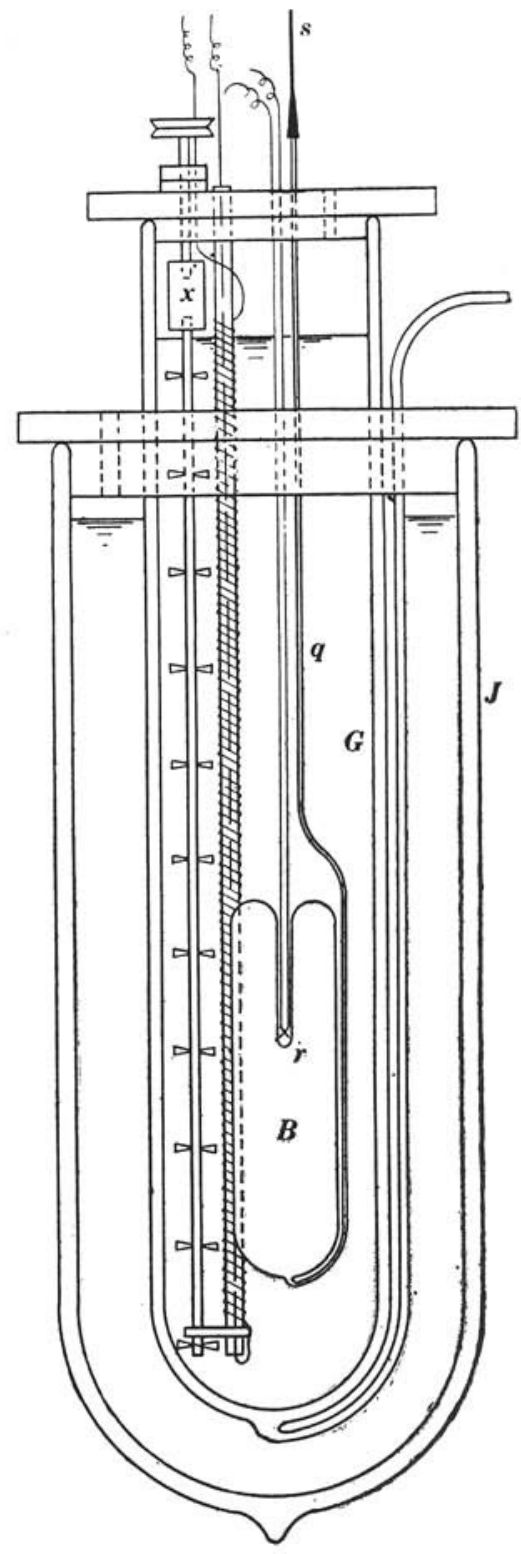

Fig. 7 
A comparison of values computed fron (13a) and (14) with those found by Dalton is given in Tables XI and XII In calculating $\mu, C_{p}$ has been assumed to have the constant value $341 \mathrm{cal}$ per gram, as was accepted by Dalton, in order to make the results comparable In view of the rather involved computations by means of the virial equations the agreement may be considered satisfactory and lends support to the mathematical form of the equation of state

\section{Description of the Apparatus}

\section{The Bulb}

The bulb B ( $\mathrm{F}_{1 \mathrm{~g}} 7$ ) is of fused quartz, $135 \mathrm{~mm}$ long and $33 \mathrm{~mm}$ outside diameter The thickness of the walls is approximately $075 \mathrm{~mm}$ During the earlier experiments a reentrant tube $r$, about $3 \mathrm{~mm}$ in diameter and $45 \mathrm{~mm}$ long was provided at the top of the bulb to receive a thermocouple The bottom of this tube was finally fractured, owing to the freezing of a small amount of water which condensed therein on standing over from a previous experiment In repairing the bulb the reentrant tube was removed, as it had not been found altogether satisfactory The volume of the first form, with reentrant tube, was $9131 \mathrm{c} \mathrm{c}$ at room temperature The volume of the present bulb is 9186 c.c. At the bottom of the bulb there is fused a quartz capillary, $q$, fashioned in the manner shown, which extends above the top of the vessel containing the bath. The end of the quartz capillary is ground into a conical steel cap and cemented with de Khotinsky cement A silver capillary s soldered into the upper end of this cap and serves to connect the bulb with the manometer The length of the quartz capillary is $50 \mathrm{~cm}$ and its volume $000316 \mathrm{cc}$ per $\mathrm{cm}$. The bulb is supported by means of a quartz rod, $Q$ (Fig 12), fused to its top and which is cemented into a brass collar screwed to the cryostat cover

The choice of fused quartz as bulb material rests mainly upon its small coefficient of thermal expansion and its supposedly less tendency to adsorb gases If glass were used, its thermal expansion would have to be known very accurately The values of the 
coefficient of expansion of quartz were taken from an analysis of the existing data by R S Taylor and L B Smith ${ }^{26}$ of this laboratory

The following relation was used for the true linear temperature coefficient of expansion, $\lambda$, of quartz below $0^{\circ} \mathrm{C}$.

$$
\log _{10}\left(\lambda \times 10^{7}+19\right)=15414-\frac{50789}{T}
$$

Quartz exhibits a maxımum density at about $-80^{\circ} \mathrm{C}$ and its mean coefficient of expansion passes through zero at $-148^{\circ} \mathrm{C}$ This property makes it especially desirable as a thermometric gas container at low temperatures

The change in volume of the bulb with pressure was determined as follows The bulb and a portion of the quartz capillary were filled with water and placed in a horizontal position The capillary was then connected through a three-way stopcock to a vertical tube and the latter partly filled with mercury, the lower end of the mercury being in contact with the surface of the water in the capillary The length of the mercury column was then increased, and the displacement of the contact surface between the mercury and water noted The volume per unit length of the capillary being known, the change of volume with pressure could be determined after making a correction for the compressibility of the water By means of the three-way stopcock, the excess of mercury could be drained from the apparatus and the experment repeated The mean of four such measurements gave the pressure coefficient of the bulb as $.0110 \mathrm{c} \mathrm{c}$ per atm \pm 00003 The figure given by Chappuis ${ }^{27}$ for the quartz bulb used by him is 000444 c.c per atm, reduced to the same volume It is probable that th difference is due to the thinner walls of the thermometer bulb

26This will be published in a forthcoming paper on the density and vapor pressure of ether at low temperatures The papers consulted in connection with the thermal expansion were:

Holborn and Henning, Ann der Phys 10, p. 446, 1903

Scheel and Chappus, Wiss. Abh Phys Tech Reichsanstalt, 4, p 54, 1904

Harlow, Proc Roy Soc Lond, 24, p 30, 1912.

Henning, Ann der Phys. 22, p. 606, 1907.

Scheel and Dorsey, Phys Rev 27, p 101, 1907.

Randall, Phys Rev., 3a, p 216, 1910.

27 Chappus, Trav Men Bur. Inst , 6, 1888. 


\section{The Connecting Capillary}

The internal diameter of the silver capillary, connecting the bulb with the manometer, was determined from measurements of its length, weight, and external diameter: the density of the silver being taken as 105 The internal diameter thus found was $0457 \mathrm{~mm}$ The length of this connection is $144 \mathrm{~cm}$ and its volume consequently $000164 \mathrm{c} \mathrm{c}$ per $\mathrm{cm}$

The lower end of the s1lver capillary connects with a capillary of glass, $g$ (Fig 8), $15 \mathrm{~cm}$ long, which is cemented into the steel cap, $k$, of the short manometer tube The introduction of this glass capillary is a safeguard to prevent mercury from reaching the silver tube should the level inadvertently be raised above the contact point It served this purpose on two occasions * The volume of the glass section was found to be 0296 c.c

\section{The Manometer}

The manometer tubes, $C$ and $C^{\prime}$ (F1g 8), are of pyrex glass specially selected for uniformity of bore and straightness, their internal diameter being $15 \mathrm{~mm} \dagger$ The tubes are fastened into the wells of the manometer base $D$ through rubber stoppers forced tight by means of the brass clamps $d$ The long tube is supported near the top by a centering device on the cover plate of the manometer frame $A$ The under side of the short tube cap $k$ is provided with a steel needle point $03 \mathrm{~mm}$ long This detail is shown in the enlargement Exact contact between the point and the mercury meniscus is determined by placing the gap in series with a small electromagnetic interrupter and telephone receiver. The long tube is connected to a vaccum pump and mantained exhausted, so that the indications are independent of barometric pressure

The manometer base $D$ is of steel $20 \times 10 \times 10 \mathrm{~cm} \quad$ It is screwed to a steel leveling stand $L$ (Fig 10), the whole resting on two massive blocks of slate The manometer tubes are connected by a

* A small valve could of course be used instead, but this seemed an unnecessary complication and one almost surely destined to provide trouble.

t The tubes were calibrated for bore and the correction for capillary depression was found to be negligible. 


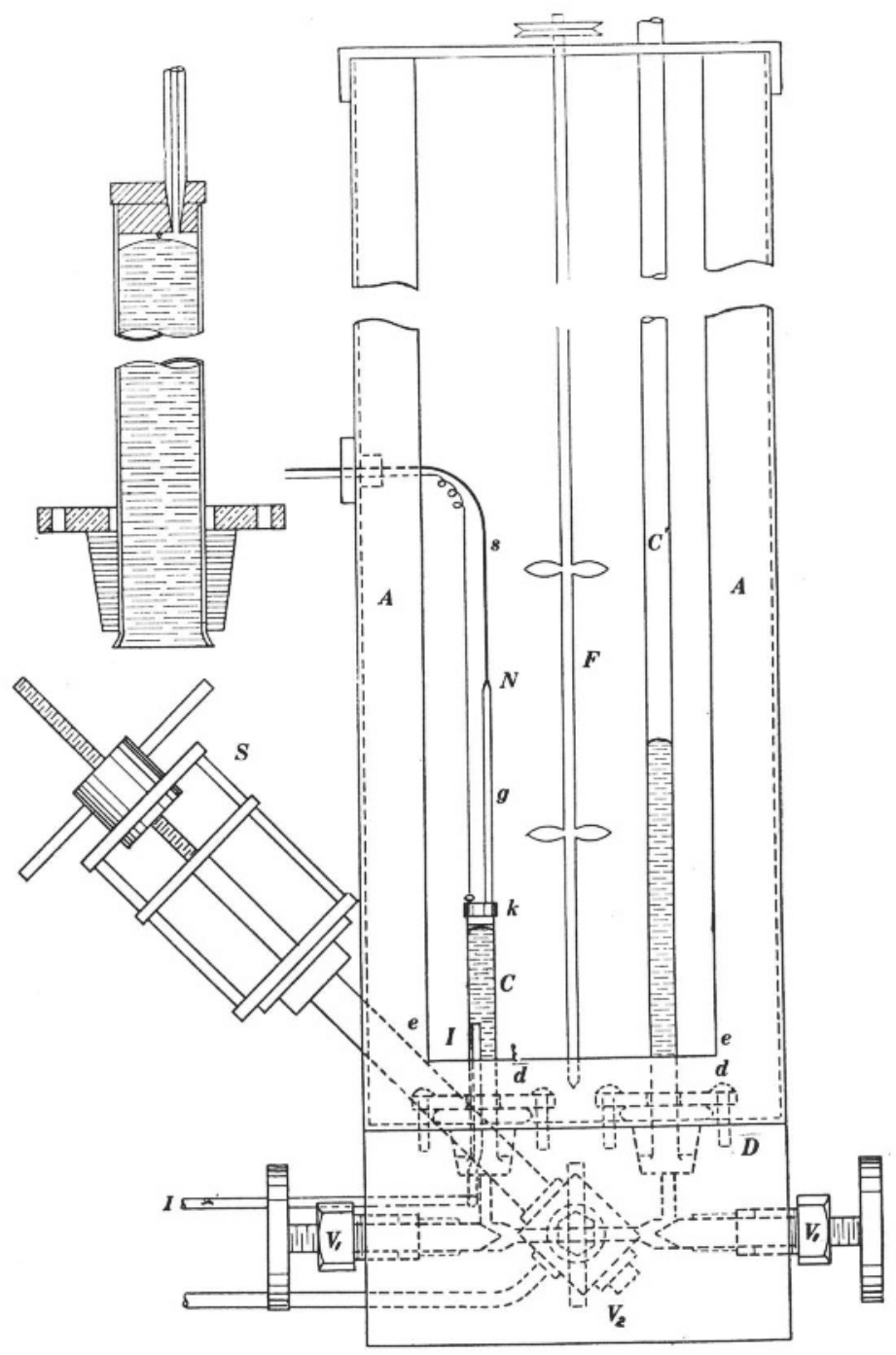

Fig. 8 
passage $1.6 \mathrm{~mm}$. in diameter A second passage at right angles to the first and half way between the tubes makes connection with the mercury reservour

Each manometer tube is provided with a shut-off valve $V_{1}$ The valve detals are shown in Fig 9 In closing the valve the piston $P$ moves forward without rotation, thereby preserving the

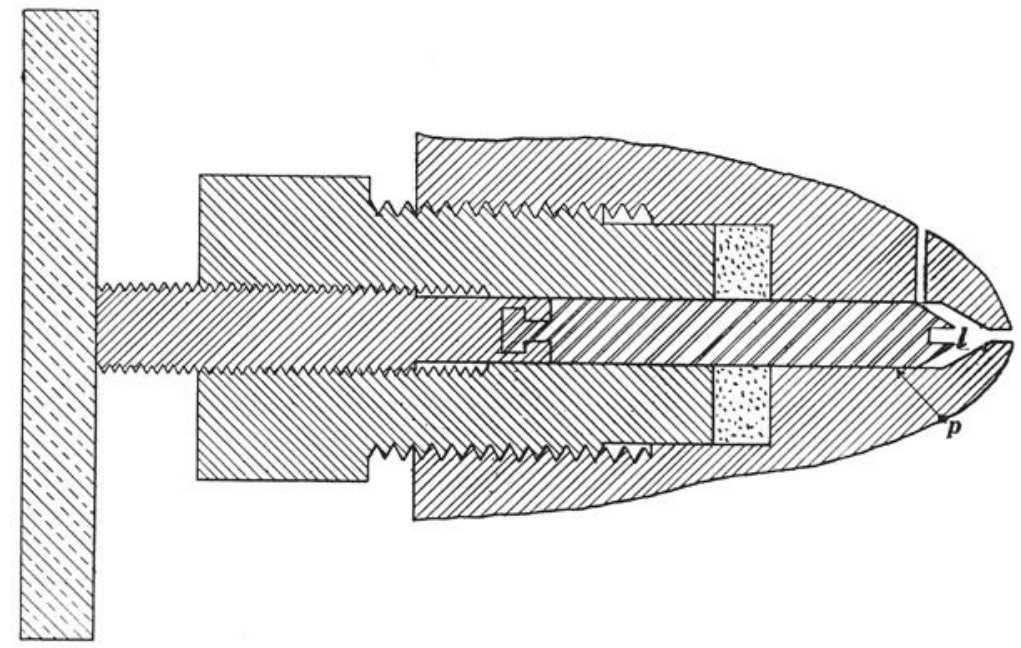

Fig. 9

packing from loosening The end of the piston is cup-shaped, $l$, and its taper is $05^{\circ}$ less than that of the seat. In this way a firmer seating is realized than with the ordinary form

The mercury reservoir, an ordinary lift-bulb mounted between vertical guides, connects with the manometer base through the rubber pressure tubing $R$ (Fig 8 ) and the shut-off valve $V_{2}$ The steel block containing this valve is threaded into the base 
and made tight with an aluminum washer The reservoir is used only for rough adjustment of the mercury level The valve $V_{2}$ is then closed and fine adjustment made by means of the injector $S$ One turn of the handle raises the level of the mercury in the short tube about $004 \mathrm{~mm}$

The frame $A$ of the manometer is fashioned from an iron channel section The section was cut at the corners $e e$, bent into a $U$ form and the corners welded The bottom and faces were planed smooth It is fastened to the base by screws and made tight by an impregnated paper gasket Sheets of plate glass are screwed to front and back These faces were made water-tight with heavy shellac and the outer edges sealed with litharge and glycern cement A stirrer, $F$, provides crculation of the bath liquid, the temperature of which is given by a calibrated Baudin thermometer $t\left(\mathrm{~F}_{1 \mathrm{~g}} 10\right)$ graduated to $01^{\circ} \mathrm{C}$

Kerosene was used as a bath liquid durng the greater part of the measurements The rubber stoppers seating the manometer tubes were covered with a thick layer of shellac to prevent their disintegration After more than a year's use the kerosene finally reached the stoppers and they had to be replaced Thereafter water was used instead of kerosene The interior surfaces of the frame and the base were covered with red lead paint to prevent rusting and then painted white to improve the illumination of the columns

Gas is admitted to the bulb through the tube $I$ (Fig 8) The mercury is allowed to fall below the upper end of $I$, the tube now remainnng filled with mercury back to the stopcock 1 (Fig 10) This is drained out into the trap $T$ When the bulb has been loaded the mercury is allowed to ascend in the short manometer tube and the inlet tube is again filled with mercury back to 1 .

\section{The Cathetometer}

The difference in level of the fixed point and the column in the long tube was measured with a Gaertner cathetometer This instrument possesses a steel scale which was compared with a Gaertner standard meter (No 1768) calibrated by the Bureau of Standards The scale error was found sensibly constant and 
amounted to $000002 \mathrm{~cm}$ per $\mathrm{cm}$ Taking the coefficient of expansion of steel to be $11 \times 10^{-6}$, the scale correction is given by the following formula

$$
H_{c o r}=H_{o b s}\left[1+11 \times 10^{-6}(t-20)+20 \times 10^{-6}\right]
$$

The instrument is fitted with a micrometer screw attachment by which $001 \mathrm{~mm}$ can be read and $0001 \mathrm{~mm}$ estimated With practice it was found that successive readings deviated by not more than a few thousandths of a millimeter

\section{The Cryostat}

The thermometer bulb is mounted in the form of cryostat shown in Fig 7 The inner vessel $G$, containing the bath, is of pyrex glass and double-walled The space between the walls is connected to the vacuum pump and can be exhausted to any desired degree The length of this vessel $1540 \mathrm{~cm}$ and its internal diameter $67 \mathrm{~cm} \quad$ It is closed by a cover of asbestos wood To this cover are attached a heater and a stirrer, the resistance wire of the heater being wound on a glass rod with asbestos string insulation between the windings To minimize heat conduction a vulcanite section $x$ is placed in the stirrer shaft just beneath the cover The bath vessel is cemented with de Khotinsky cement into the asbestos wood cover of the outer Dewar tube $J$ This latter is $40 \mathrm{~cm}$ long with an internal diameter of $135 \mathrm{~cm}$ The outer vessel, and also its cover, beanng the inner vessel, are mounted in vertical guides between the surfaces of a double-decked table For the bath liquid normal pentane was used, which remains quite liquid down to $-145^{\circ} \mathrm{C}$ For comparisons below this point the thermometer was immersed directly in liquid air or oxygen

The outer vessel being filled with liquid air, maintained at a farly constant level, the temperature of the bath can readily be held constant at any desired point by suitably regulating the heating current and the degree of exhaustion withn the walls of the bath vessel In practice, the walls are pumped out to the right degree as determined by experiment and the temperature control during the observations effected solely by hand regulation of the heater current Over a penod of fifteen or twenty minutes the temperature can be held to the same value within $001^{\circ} \mathrm{C}$ 


\section{Auxiluary Apparatus}

Fig 10 illustrates the general arrangement of the apparatus $M$ represents a supply of helium, $K$, a hydrogen generator, and when nitrogen was used it was introduced at $E$ A Toepler pump

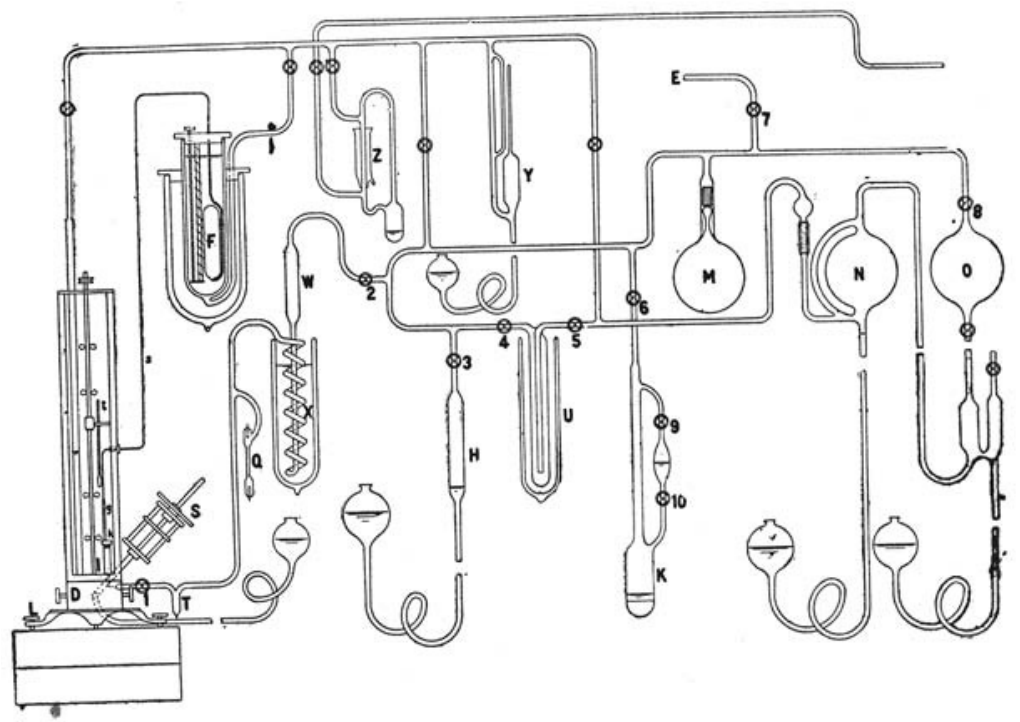

Fig. 10

$N$ served to transfer the helium from its contanner to the gas reservoir $O$ In the cases of hydrogen and nitrogen, where fresh gas could be generated whenever needed, the Toepler pump was not used, the reservorr being filled directly from the generator $U$ is a carbon adsorbing tube to be immersed in liquid arr in purfying the helium The gas could be crrculated repeatedly through the purifyng tube by means of the pump $H$ is an auxuliary lift pump for convenience in loading the thermometer Before entering the bulb the gas passed through the purifying tube $W$ containing soda lime and phosphorus pentoxide and the 
spiral $\mathrm{X}$ immersed in liquid air A Geissler tube $Q$ served as means of checking the purity of the gas At $Y$ and $Z$ are shown a McLeod gauge and mercury diffusion pump The latter is backed up by a rotary oil pump capable of giving $001 \mathrm{~mm}$ With the two in series the apparatus could be exhausted to better than $1 \times 10^{-5} \mathrm{~mm}$

\section{Sources of Error}

The three main sources of error in gas thermometry involve the control of the volume of the bulb, the volume and temperature of the dead space, and the temperature of the mercury columns For the present it is assumed that the total mass of the thermometric gas exists only in the gas phase, and we reserve for discussion in another place, the error which may result from adsorption of the gas on the walls of the bulb at low temperatures

Assuming that it is desired to measure a temperature of $-100^{\circ}$ $\mathrm{C}$, it is possible to forecast the accuracy with which this can be accomplished The actually observed pressure can be measured to $001 \mathrm{~mm}$ The corrections for temperature expansion of the cathetometer scale and the reduction of the mercury column to standard gravity can be made with sufficient accuracy to introduce no appreciable error If the recorded pressure is about $500 \mathrm{~mm}$ the correction for temperature of the mercury columns (ca $25^{\circ} \mathrm{C}$ ) is of the order of $25 \mathrm{~mm}$, which must be known to 02 per cent and the coefficient of expansion of mercury together with the mean temperature of the manometer must each be known to 014 per cent Use was made of the coefficient of expansion of mercury given by Callendar and Moss ${ }^{28}$ The mean temperature of the manometer must then be known to $\pm 003^{\circ} \mathrm{C}$ The necessity of jacketing the columns, therefore, is apparent The usual procedure of placing two or three thermometers along the column in air is believed to be inadequate With the columns immersed in a stirred bath of kerosene or water, the temperature of which is given by a calibrated thermometer readable to $001^{\circ} \mathrm{C}$, we feel hat the necessary condition of determining the average temperature to $003^{\circ}$ is certainly fulfilled The correction for difference in

28 Callendar and Moss, Phil Trans, 1911. $a=0000180555+00,1244 t+$ $00_{10} 254 t^{2}$ 
level of the bulb and contact point only amounts to one or two hundredths of a millimeter and can be accurately applied The dead space correction at the 1ce point amounts to about $004 \mathrm{~mm}$ and at $-100^{\circ} \mathrm{C}$ to $15 \mathrm{~mm}$ This correction should then be known to 02 per cent in order to introduce no further error It follows that the temperature of the dead space should be known to $\pm 01^{\circ} \mathrm{C}$ and its volume to 014 per cent Both these conditions can be realized Thus the pressures, $p_{\circ}$ and $p$, can be determined in the case under consideration to $001 \mathrm{~mm}$ or about $1 / 50,000$

The correction term for change in volume of the bulb must be accurate to about ten per cent in the case of fused quartz, if the precision previously laid down is to be maintained If a glass bulb is used, the necessary precision of this term would be of the order of one per cent, which for glass would be very difficult to realize and much uncertainty has undoubtedly been introduced into gas thermometry because of the uncertainty of the expansion data In the case of quartz, both the thermal expansion and that due to pressure can be determined easily with the necessary precision It thus appears that the bracketed term of the temperature formula (3) can be determined to $1 / 20,000$ under the conditions assumed

We now have the temperature given as the product of three factors, $\stackrel{t}{\epsilon}_{v}, p_{0}$, and the bracketed term The estimated precision of these three quantities is $1 / 12,000,1 / 60,000$, and $1 / 20,000$ respectively The percentage error in the temperature can thus be put at 001 per cent Hence, at $-100^{\circ} \mathrm{C}$ the temperature is determinable to $\pm 001^{\circ} \mathrm{C}$ At the boiling point of oxygen, we believe the limit of our present accuracy to be $\pm 002^{\circ} \mathrm{C}$

\section{Description of the Experiments}

\section{A. Indirect Determination of the Dead Space Volume}

The volume of the dead space could be directly measured with the exception of that part comprised between the level of the contact point and the mercury meniscus This cannot be sufficrently accurately calculated on the assumption that the meniscus is a segment of a sphere Moreover, the ellipsordal formula used 
by Travers, Senter and Jaquerod ${ }^{29}$ is not in agreement with that used by Chappuis, ${ }^{27}$ based on the work of Desains These two formulæ applied to our case and comprising the volume between the under surface of the steel cap $k$ and the meniscus gave 0159 c c and 0175 c.c respectively Since the more recent measurements of Scheel and Heuse ${ }^{30}$ upon meniscus volumes were not known at the time, it was decided to determine the volume experimentally by an indirect method

Assuming the coefficient of pressure increase of air to be given correctly by calculation from the equation of state, the volume of the dead space could be found after determining the ice and steam points on the gas thermometer, since it would then be the only unknown quantity $\mathrm{A}$ description of the procedure in determining ice and steam points will be given in the next section It will suffice here to record the dead space volume thus found On taking the contact space volume to be 0196 c.c , we have the following measurements of the coefficient of pressure increase of air:

\begin{tabular}{llc}
$\substack{100 \\
\epsilon_{v}}$ & Air $p=60788 \mathrm{~mm}$ & \\
00036682 & & Date \\
00036691 & $1 / 21 / 21$ \\
00036689 & $1 / 24 / 21$ \\
\hline $00036687 \pm 0$ & 0.3 mean & $1 / 29 / 21$ \\
0 &
\end{tabular}

The value calculated from the equation of state is 00036690 * Subsequently, the experimental results of Scheel and Hęuse have come to light and applying these data to the dimensions of the contact space there is found 0197 c.c The agreement is astonishingly close in view of the involved manner in which the volume 0196 was deduced and furnishes evidence of the accuracy of the apparatus and procedure

The total volume of the dead space is $0886 \mathrm{c} \mathrm{c}$ The ratio of dead space to bulb is thus 00097 This is larger than might be ${ }_{\epsilon_{0}}^{* 100}=000366118+129 \times 10^{-10} \mathrm{p}_{0} \quad(\mathrm{~mm}$.)

29 Travers, Senter and Jaquerod, Ph11 Trans. 200, p. 110, 1903.

30 Scheel and Heuse, Ann. der Phys , 33, p. 291, 1910 
desired; but inasmuch as 60 per cent of the dead space is within the manometer, where its temperature is accurately known, the dead space correction, though fairly large, is calculable with considerable exactness

\section{B. Coefficient of Pressure Increase of Nitrogen}

As a test of the operation of the apparatus and of the value determined for the dead space volume, ${\underset{\sigma}{0}}_{0}$ for nitrogen was next determined This could be then compared with the value calculated from the equation of state

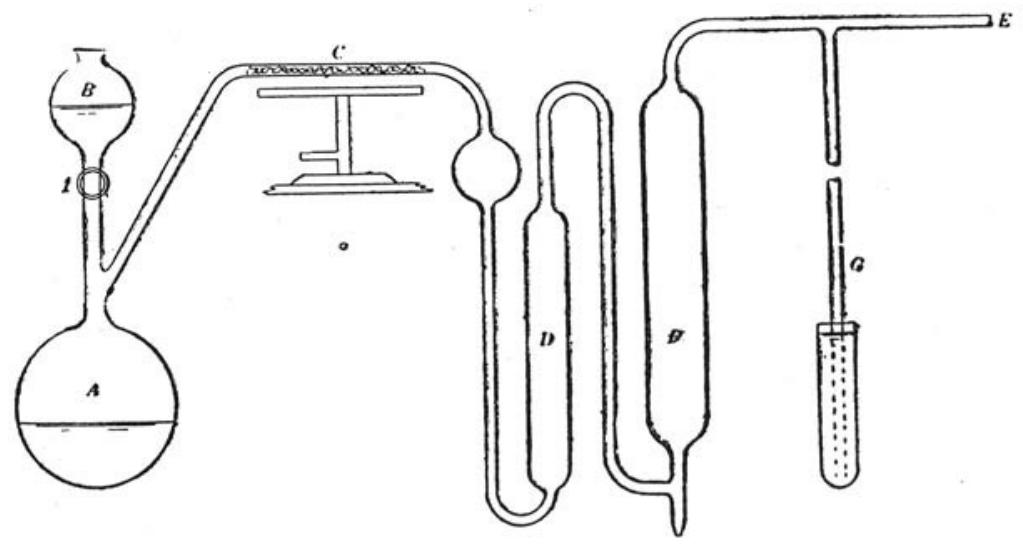

Fig. 11

The nitrogen was prepared in the usual manner by the interaction of ammonium sulphate and sodium nitrite The generating train is shown in Fig 11 A solution of 70 grams of $\mathrm{NH}_{4} \mathrm{SO}_{4}$ in 120 c.c of water was placed in $A \quad B$ contained a solution of 40 grams of $\mathrm{NaNO}_{2}$ in 50 c.c of water The nitrite could be admitted gradually into $A$ through the stopcock 1 , the vessel $A$ being warmed in a water bath The reaction is autocatalytic, and if the temperature is not controlled, proceeds with too great rapidity The gas passed over heated copper in the quartz tube $C$ and then through sulphuric acid in $D$ and phosphorus pentoxide in $F$. The tube $G$, dipping into mercury, acted as a safety valve. The gen- 
erating train was connected to the rest of the system at $E$ (Fig 10). Before preparing the gas the whole system was pumped out and repeated rinsing with the gas preceded the final exhaustion and filling of the reservoir $O$ The pressure within the reservoir could be read by means of the mercury column $J$

The reservorr having been filled with nitrogen at about one atmosphere pressure, the generating train was now shut off at 7 and the rest of the system completely exhausted Stopcocks 4 and 5 were kept closed, the carbon purifying tube being used only in the case of helium By lowerng the mercury in the short manometer tube below the gas inlet and allowing the mercury in the inlet passage to flow into the trap $T$, the bulb could be placed in communication with the pump through the stopcock 2 The bulb was maintaned at $360^{\circ} \mathrm{C}$ within an electric heater and exhausted to $00001 \mathrm{~mm}$ at this temperature A small amount of gas was now introduced and after standing a few minutes again pumped out This rinsing process was repeated four or five times before the bulb was allowed to cool and finally loaded In adjusting the pressure to the desired amount the lift pump $H$ was of use Gas could be admitted into $H$ from the reservorr and then after closing 8 could be pushed over into the bulb Durng the filling the coil $X$ was cooled by liquid air to remove any condensible constituents Exammation of the spectrum of the gas in the Geissler tube $Q$ furnished satisfactory evidence of its purity

To determine the 1ce point the bulb was placed in a large Dewar tube and surrounded with shavings of distrlled water ice Ice cold distilled water was added, immersing the bulb to a depth of two or three inches The dead space volume was considered in two parts - one at the temperature of the manometer, the other, comprised between the top of the bath and the cover, at the mean temperature of room and bath In reading the pressure four observations of the height of the fixed point* and of the mercury in the long column were taken Durng any run the maximum deviation was not greater than $001 \mathrm{~mm}$ The 1ce points before and after the steam points were found to be

* The fixed point did not vary during any given run, but its height was found to depend slightly upon the pressure of the gas, due presumably to a small amount of give in the rubber seating of the tube 


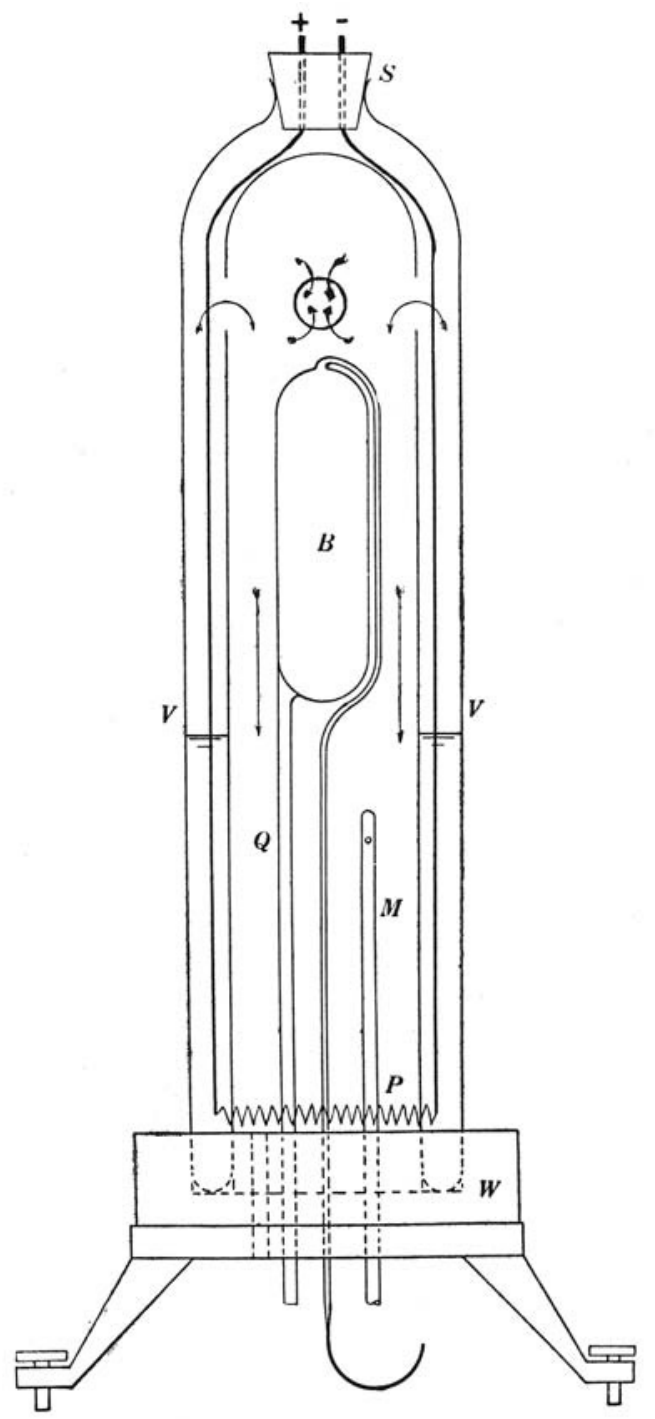

Fig. 12 
Ice Point, $N_{2}$
$\quad m m$

65380

65382
Date

$3 / 18 / 21$

$4 / 20 / 21$

The steam point was determined in a specially designed boiler, illustrated in Fig 12 The double-walled vessel $V$ is of pyrex glass, $40 \mathrm{~cm}$ long and $67 \mathrm{~cm}$ internal diameter Distilled water is placed in the annular space and is heated by a platinum corl $P$ immersed directly in the liquid The Monel lead wires are brought out through the stopper $S$ The steam passes through the openings $A$ and down over the bulb, issung through an opening in the asbestos wood base $W$ The whole is mounted on a brass leveling stand A glass tube $M$ connects with a U-tube water manometer to indicate the excess of steam pressure over atmospheric When in use, a prpe cover is slipped down over the vessel for insulation This type of boller was found to give excellent results, the water boiling gently and continuously and the steam pressure not more than one millimeter of water above that of the atmosphere The readings were found independent of the rate of bolling within wide limits

Three steam points were taken with the nitrogen filling as follows

\section{Steam Point, $N_{2}$ \\ $m m$}

89506

89491

89439

\section{Temperature}

${ }^{\circ} \mathrm{C}$

10062

10057

10034
Date

$3 / 23 / 21$

$3 / 23 / 21$

$3 / 24 / 21$

The values for ${ }_{0}^{100}$ from the mean of the ice points and each steam point are given in the first column of Table XIII The value calculated from the equation of state* and that given by Henning and Heuse ${ }^{\mathbf{3 1}}$ are also given for comparison

The difference between our measured value and that calculated from the equation of state amounts to $1 / 7350$ The calculated

* For $\mathrm{N}_{2}=000366118+121 \times 10^{-10} p_{\circ}(\mathrm{mm})$

31 Henning and Heuse, Zeit. $f$ Phys , 5, p 285, 1921. 
TABLE XIII

Coefficient of Pressure Increase for Nitrogen $p_{\mathrm{o}}=65381$

\begin{tabular}{c|c|c}
\hline Measured $\times 10^{7}$ & Calc, Keyes* $\times 10^{7}$ & $\begin{array}{c}\text { Measured, } \\
\text { Henning and Heuse 31 } \\
\times 10^{7}\end{array}$ \\
\hline 36698 & 36691 & 36692 \\
36693 & & \\
36698 mean & & \\
\hline 36696 mean & \\
\hline
\end{tabular}

value we believe the more nearly correct, especially in view of its agreement with the measurements of Henning and Heuse It was proposed in measuring temperatures to utllize the calculated values of the coefficients and the above measurements were a test of the sufficiency of the apparatus We believe that in general a precision of $1 / 10,000$ is realizable

\section{The Diffusion of Helum and Hydrogen Through Quartz}

It was onginally contemplated to use helium as thermometric gas To this end the helium in the globe $M\left(\mathrm{~F}_{1 \mathrm{~g}} 10\right)$ - furnished in a high state of purity by the Linde Air Products Co of Buffalo - was transferred to the reservorr $O$, being circulated repeatedly through the charcoal tube $U$ immersed in liquid air The thermometer bulb was loaded to an 1ce-point pressure of about $621 \mathrm{~mm}$

As soon as measurements were undertaken it became apparent that gas was being lost from the bulb In two days the 1ce point dropped from $62074 \mathrm{~mm}$ to $61929 \mathrm{~mm}$, the bulb remaining at about $27^{\circ} \mathrm{C}$ during the interval The pressure inside being less than atmospheric, the possibility of leakage was excluded It was known that helium diffuses readily through quartz at high temperatures ${ }^{\mathbf{3 2}}$, but such a large effect at ordinary temperatures had not been suspected The rate of diffusion at $27^{\circ} \mathrm{C}$ and 682 $\mathrm{mm}$ internal pressure was found to be $003 \mathrm{~mm}$ per hour At $100^{\circ} \mathrm{C}$ the rate appeared nearly ten times as great Subsequently we have read of a similar expenence of Henning, ${ }^{33}$ who found the rate of diffusion at room temperature and $700 \mathrm{~mm}$ internal pressure to be $001 \mathrm{~mm}$ per hour in the case of the bulb used by him

32 Jaquerod and Perrot, C r , 139, p 789, 1904

33 Henning, Zeit f Phys, 5, p 264, 1921

* For $\mathrm{N}_{2}=000366118+121 \times 10^{-10} \mathrm{p}_{0}(\mathrm{~mm})$ 
On account of the rapid decrease in the rate of diffusion with lowering of the temperature it seems probable that it would become negligible at $0^{\circ} \mathrm{C}$ If the bulb of the thermometer were not heated above this point it might be possible to utilize the attractive combination of helium in quartz for the measurement of low temperatures, but owing to the difficulties of this procedure the use of helium in the present instance was discarded

Hydrogen was the next choice It was prepared by the action of pure sodium amalgam upon water in the type of generator shown at $K\left(\mathrm{~F}_{1 \mathrm{~g}} \mathrm{10}^{\mathrm{N}}\right)$ The small bulb in the side tube contained air-free water which could be admitted at w1ll into the lower bulb containing the amalgam The hydrogen was dried in the process of loading by passing through the pentoxide tube $W$ and the spiral $X$

Diffusion of the gas through the walls of the bulb was again found, although to a much less extent than in the case of helium The 1ce-point pressure of the initial loading was $64511 \mathrm{~mm} \mathrm{~A}$ succession of steam points gave lower pressures each time, the drop amounting to $04 \mathrm{~mm}$ in four days An estmate of the rate of diffusion at any definite temperature cannot be given, it being only possible to conclude that at $100^{\circ} \mathrm{C}$ it is considerably greater than $0004 \mathrm{~mm}$ per hour

The possibility of using hydrogen in quartz is by no means excluded, although the rate of diffusion at $100^{\circ}$ is large enough to cause some difficulty in determining the coefficient of pressure increase It had been decided, however, to employ nitrogen also in the investigation and with this gas duffusion causes no trouble Later a comparison was made with the hydrogen thermometer.

\section{Measurements with the Nitrogen Thermometer Thermocouple Calbbration}

With the nitrogen thermometer a calibration was made of a multiple copper-constantan thermocouple down to the boiling point of oxygen The thermocouple consisted of six copperconstantan couples in series, each wire of No $30 \mathrm{~B} \& \mathrm{~S}$ gauge The junctions were silver soldered by bringing a tiny drop of molten silver solder into contact with the junction, thus avoid- 
ing direct heating of the wires with the blow pipe flame Each lead was covered with bakelite varnish and baked at $100^{\circ} \mathrm{C}$ for several hours They were further insulated from each other with silk floss and then tied together with silk thread to form a pencil three millimeters in diameter and five centimeters long The "cold junction" was kept in ice within a small thermos bottle The "hot junction" could be introduced into the reentrant tube of the thermometer bulb With this arrangement there seemed no doubt that the temperature of the indicating junction and that of the gas within the bulb would be the same

The electromotive force of the thermocouple was measured on a Leeds and Northrup Type K potentıometer in conjunction with a high sensibility galvanometer of seventeen ohms internal resistance The whole electrical system was placed on interconnected metal plates in order to be shielded from surface leakage due to external potential differences ${ }^{34}$ Very little trouble was experienced from leakage effects except during one period of extremely damp weather when measurements had to be suspended The indications of the thermocouple were reproducible to one microvolt

The first calibration was made at twelve temperatures ranging from $-1833^{\circ} \mathrm{C}$ to $-18339^{\circ} \mathrm{C}$ on the nitrogen scale A check calibration at $-18315^{\circ} \mathrm{C}$ was made two months later, and after a further period of three months, another calibration was undertaken in the range $-5112^{\circ} \mathrm{C}$ to $-13054^{\circ} \mathrm{C}$ This latter calibration furnished a very good check on the reliability of the gas thermometer and the constancy of the thermocouple, for 1 t was made under quite different conditions The quartz thermometer bulb had been broken during the intervening period and in its new form was without the reentrant tube The individual junctions of the thermocouple had, moreover, been separated and each protected by a thin tube of glass They were then equally spaced about the crrcumference of the bulb The ice-point pressure of the nitrogen thermometer at this time was somewhat higher, $72788 \mathrm{~mm}$, being a new loading The results were in very satisfactory agreement with the first calibration, the maximum deviation being $004^{\circ} \mathrm{C}$ It would thus appear that a properly prepared

34W P. White, J. Am Ch Soc., 36, p 2011, 1914. 
and protected copper-constantan thermocouple furnishes a satisfactory and reproducible method of measuring low temperatures, at least down to $-183^{\circ} \mathrm{C}$ To increase its applicability there ought to be a number of reliable fixed points in the low temperature range The second part of this paper w1ll give determinations of the freezing points of certain organic compounds with this purpose in view

The relation between temperature and electromotive force of the couple employed was found to be represented with a maximum error of $018^{\circ} \mathrm{C}$ by the following formula

$$
E=01486(t)^{2137}-22220 t
$$

With the exception of the range from $-37^{\circ}$ to $-91^{\circ}$ the deviation of the values calculated from this formula from those actually observed is nowhere greater than $005^{\circ} \mathrm{C}$ The relation can thus be used to calculate temperatures from observed electromotive forces when supplemented by a deviation plot The data on the calibration of the thermocouple are set forth in Table XIV The last column shows the deviations of the actually observed tem-

TABLE XIV

Thermocouple Calibration

$e_{c}=01486 t^{2.137}-22220 t$

\begin{tabular}{|c|c|c|c|c|c|c|c|}
\hline \multirow[b]{2}{*}{ Date } & \multicolumn{2}{|c|}{ Pressure } & \multirow[b]{2}{*}{${ }^{t_{N_{2}}}$} & \multirow[b]{2}{*}{$\mid \begin{array}{l}E \quad M \quad F \\
\text { Observed } \\
10^{-6} \text { volts }\end{array}$} & \multirow{2}{*}{$\begin{array}{c}E M F \\
\text { Calcu- } \\
\text { lated } \\
10^{-6} \text { volts }\end{array}$} & \multirow{2}{*}{$\mid \begin{array}{c}E_{c a l} \\
-E_{o b s} \\
10^{-6} \\
\text { volts }\end{array}$} & \multirow[b]{2}{*}{${ }^{t c a l}-{ }^{\circ} \mathrm{C} o b s$} \\
\hline & $\underset{m m}{P_{\circ}}$ & $\begin{array}{c}P_{t} \\
m m\end{array}$ & & & & & \\
\hline $4 / 29 / 21$ & 65383 & 60985 & -1833 & 3998 & 3999 & +1 & +0005 \\
\hline $2 / 21$ & & & -2926 & 6303 & 6300 & -3 & -0014 \\
\hline $5 / 2 / 21$ & 65383 & 56223 & -3819 & 8121 & 8129 & +8 & +0041 \\
\hline $4 / 29 / 21$ & 65383 & 53954 & -4765 & 9992 & 10015 & +23 & +0117 \\
\hline $4 / 29 / 21$ & 65383 & 507 & -6097 & 12544 & 12578 & +34 & +0177 \\
\hline $4 / 27 / 21$ & 65383 & 46 & -7725 & 15530 & 15556 & +26 & +0146 \\
\hline 21 & 65383 & 42493 & -9543 & 18674 & 18678 & 4 & +0024 \\
\hline $4 / 29 / 21$ & 65383 & 370 & -118.11 & 22254 & 22258 & +4 & +0027 \\
\hline $4 / 28 / 21$ & 65383 & 34537 & -12558 & 23785 & 23791 & +6 & +0041 \\
\hline 40821 & 65383 & 32562 & -13682 & 24941 & 24944 & & +0022 \\
\hline $2 / 21$ & 65383 & 21388 & -18339 & 30542 & 30543 & +1 & +0010 \\
\hline $7 / 8 / 21$ & 65404 & 21452 & -18315 & 30518 & 30518 & & 0 \\
\hline $10 / 14 / 21$ & 72788 & 59137 & -5112 & 10671 & 10693 & +22 & +0113 \\
\hline $10 / 14 / 21$ & 72788 & & -77.77 & 15627 & 15649 & +22 & +0124 \\
\hline $10 / 1$ & 72788 & 45190 & -10333 & 19959 & 19965 & +6 & +0037 \\
\hline $10 / 1$ & 72788 & 37917 & -13054 & 24072 & 24071 & -1 & -0007 \\
\hline
\end{tabular}


peratures from those calculated by means of formula (15) The temperatures are those given by the nitrogen thermometer In subsequent measurements with the thermocouple the temperatures were corrected so as to be in accord with the indications of the hydrogen thermometer

\section{Platinum Resistance Thermometer Comparison}

The platinum resistance thermometer was compared with the nitrogen thermometer over the range $-30^{\circ} \mathrm{C}$ to $-183^{\circ} \mathrm{C}$ The resistance thermometer was of the flat Dickinson and Mueller type with silver sheath and steel stem of $0010 \mathrm{inch}$ wall thickness Its resistance was measured on a Mueller dial bridge made by Wollf The bridge coils were immersed in a stirred bath of kerosene, a thermostatic device keeping the temperature constant to $\pm 003^{\circ} \mathrm{C} \quad$ No measurable heating effect of the thermometer current was detected and the galvanometer responded to changes in temperature of one or two thousandths of a degree The 1ce-point resistance was found to be $255370 \mathrm{ohms}$, the fundamental interval $99606 \mathrm{ohms}$, and $\delta 151$ This latter was determined from readings on the boiling point of naphthalene $\left[21796^{\circ}+0058(p-760)\right]^{\mathbf{3 5}}$ The 1ce point did not shift by more than five or six ten-thousandths of an ohm during the period of several months the resistance thermometer was in use

The results of three comparisons are given in Table XV The general form of the deviation of the Callendar formula from the gas scale is similar to that found by Henning, ${ }^{\mathbf{3 6}}$ but the actual deviations at low temperatures are considerably less Thus at $-183^{\circ} \mathrm{C}$ the platinum resistance thermometer gave indications about $12^{\circ} \mathrm{C}$ lower than those of the nitrogen thermometer For the actual error of the platinum thermometer at low temperatures reference should be made to 1ts companson with the hydrogen thermometer

A comparison of the previously calibrated thermocouple with the corrected indications of the platinum resistance thermometer was obtained by measuring the freezing point of ammonia with each instrument The freezing points so determined agreed within

35 Bur St Circ, 35, 1919.

36 Henning, Ann der Phys, 40, p 635, 1913 
TABLE XV

Comparison of Platinum Resistance Thermometer with Nitrogen Thermometer

\begin{tabular}{|c|c|c|c|c|c|c|}
\hline \multirow[b]{2}{*}{ Date } & \multicolumn{2}{|c|}{ Pressure } & \multirow[b]{2}{*}{$\begin{array}{c}\text { Resistance } \\
\text { ohms }\end{array}$} & \multirow[b]{2}{*}{${ }^{t^{t} N_{2}}$} & \multirow[b]{2}{*}{${ }^{t_{p t}} \mathrm{C}$} & \multirow[b]{2}{*}{${ }^{t_{N_{2}}}-t_{p t}$} \\
\hline & $\underset{m m}{P_{\circ}}$ & $\begin{array}{c}P_{t} \\
m m .\end{array}$ & & & & \\
\hline $11 / 21 / 21$ & 72807 & 64837 & 225149 & -2984 & -2976 & -0.08 \\
\hline $11 / 21 / 21$ & 72807 & 48347 & 161545 & -91.56 & -91.56 & 0 \\
\hline $11 / 21 / 21$ & 72807 & 42047 & 136843 & -11513 & -11527 & +0.14 \\
\hline $11 / 21 / 21$ & 72807 & 39297 & 125962 & -12543 & -12568 & +0.25 \\
\hline $11 / 21 / 21$ & 72807 & 23820 & 63740 & -18333 & -18449 & +116 \\
\hline $12 / 9 / 21$ & 72811 & 64937 & 225466 & -2948 & -29.45 & -003 \\
\hline $12 / 9 / 21$ & 72811 & 55636 & 189815 & -6429 & -6423 & -006 \\
\hline $12 / 9 / 21$ & & 45619 & 150845 & -10178 & -101.83 & +005 \\
\hline $12 / 9 / 21$ & 728 & 37101 & 117230 & -13365 & -13395 & +030 \\
\hline $12 / 20 / 21$ & & 23810 & 63699 & -183.37 & -18453 & +116 \\
\hline $12 / 21 / 21$ & 728 & 237 & 63522 & -18352 & -18470 & +118 \\
\hline
\end{tabular}

$001^{\circ} \mathrm{C}$ This agreement is especrally satisfactory in that at this temperature $(-778)$ the platinum thermometer reads higher than the gas thermometer, a fact not to be expected from the work of previous investigators The freezing point of ammonia thus determined will be given in conjunction with the other fixed points

\section{Boulung Pounts of Carbon Droxzde and Oxygen (Preliminary)}

The boiling points of carbon dioxide and oxygen were measured in a vapor pressure manometer ( $\mathrm{p} 301$ ) with the platinum resistance thermometer The bolling point of $\mathrm{CO}_{2}$ at $7202 \mathrm{~mm}$ was found to be $-7921^{\circ} \mathrm{C}$ on the scale of the nitrogen thermometer. The temperature-vapor pressure equation of Henning ${ }^{37}$ for $\mathrm{CO}_{2}$ gives $-7918^{\circ} \mathrm{C}$ at this pressure The boiling point of oxygen, corrected to normal pressure by the equation of Cath, ${ }^{\mathbf{3 8}}$ was found to be $-18355^{\circ} \mathrm{C}$, while the temperature of free boiling oxygen at normal pressure was found by direct immersion of the resistance thermometer in the liqu1d to be $-18346^{\circ} \mathrm{C}$ on the nitrogen scale.

37 Henning, Ann. der Phys , 43, p. 287, 1914.

For $\mathrm{CO}_{2}: T=\frac{194584}{1-014428 \log (p / 760)}$

38 Cath Leiden Comm, 152d, 1918.

For $O_{2}: \log p=-\frac{419.3}{T}+5.2365-000648 T$ 
In view of the fact that the best previous determinations of the oxygen point all gave values between $-18290^{\circ} \mathrm{C}$ and $-18300^{\circ}$ $\mathrm{C}$ our value appeared much too low Thus the nitrogen thermometer agreed within $003^{\circ} \mathrm{C}$ with the hydrogen thermometer of Henning, at least down to $-80^{\circ} \mathrm{C}$; but at lower temperatures deviated in the direction of values which were too low In order to determine whether this deviation was really due to a thermodynamic property of the gas, as is commonly supposed, the effect of varying the initial pressure of the gas was tried The result of this experiment has already been given ( $p$ 253), leading to the conclusion that the deviation was independent of the initial pressure between $640 \mathrm{~mm}$ and $440 \mathrm{~mm}$ No proof is thus afforded that the pressure of the nitrogen is not a linear function of the temperature at constant volume at $-183^{\circ} \mathrm{C}$ A deviation of the mitrogen scale from that of hydrogen at low temperatures is established, however, and the thermometer bulb was filled with hydrogen in order to obtain a direct companson of the two scales over the whole range of the experiments

\section{E Measurements wrth the Hydrogen Thermometer}

The thermometer was loaded with hydrogen in the manner previously described for nitrogen Owing to diffusion no attempt was made to determine the pressure coefficient experimentally, the value being obtained by calculation from the equation of state This value at the initial pressure of $7632 \mathrm{~mm}$ is 00036624 Henning gives 00036617 for the same pressure, whereas the value calculated for $1100 \mathrm{~mm}$ or 00036629 , is in almost exact agreement with the value 00036628 obtained by Onnes If the temperature of the bulb is never rased above that of the room, no serious dufficulty will be caused by duffusion Over a period of twenty days the ice-point pressure decreased at a rate of only $0013 \mathrm{~mm}$ per twenty-four hours

\section{Platınum Resistance Thermometer Comparison}

A comparison of the platinum resistance thermometer with the hydrogen thermometer was now made The cryostat previously described was avaslable for measurements down to $-145^{\circ} \mathrm{C}$, at which point the pentane bath becomes viscous Comparisons at 
a lower temperature were carried out directly in hquid oxygen. Electrolytic oxygen was dried by phosphorus pentoxide $P$ (Fig 13 ), and forced at a pressure of about twenty pounds per square inch through the copper coil $C$ immersed in liquid arr $\mathrm{A}$ continuous stream of oxygen was thus formed which could be collected in the Dewar tube $D$ and transferred to the vessel containing the thermometers

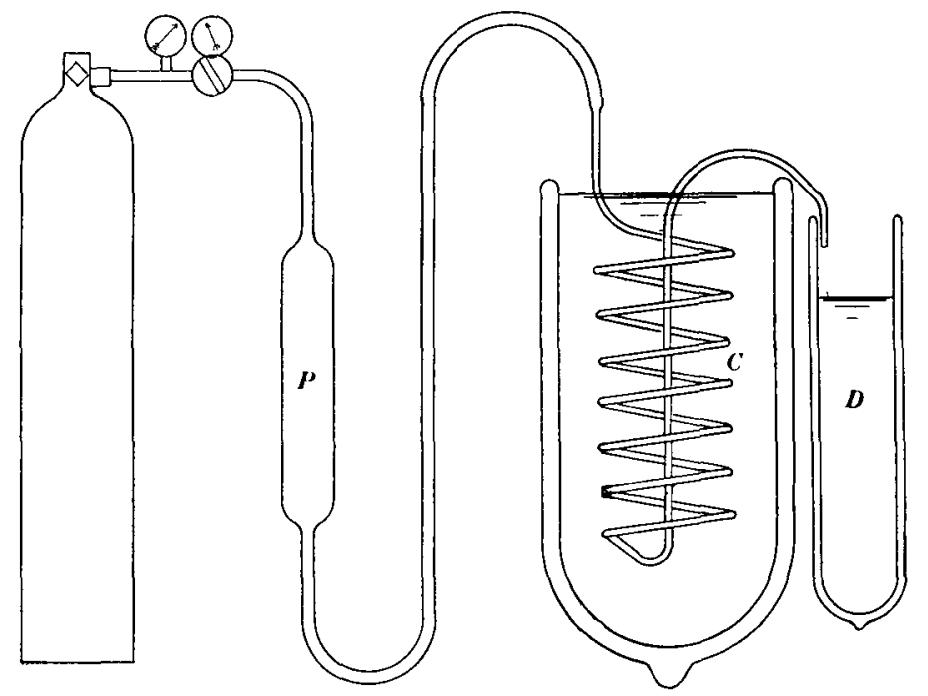

Fig. 13

The results of the comparison are given in Table XVI Curve $A$ of $\mathrm{F}_{1 \mathrm{~g}} 14$ exhibits the deviations of the temperatures derived from the platinum resistance thermometer and the Callendar formula from the hydrogen scale Curve $B$ gives the deviations of the platinum thermometer from the nitrogen scale based on Table XV and plotted against hydrogen temperatures The deviations from the hydrogen scale are considerably larger at low temperatures than those found in the case of nitrogen, but are strll smaller than the deviations found by Henning Moreover, between $0^{\circ} \mathrm{C}$ and $-83^{\circ} \mathrm{C}$ the resistance thermometer reads too high, whereas Henning found no deviation between $0^{\circ}$ and $-40^{\circ}$ and below the latter temperature the resistance thermometer indicated increasingly too low temperatures 


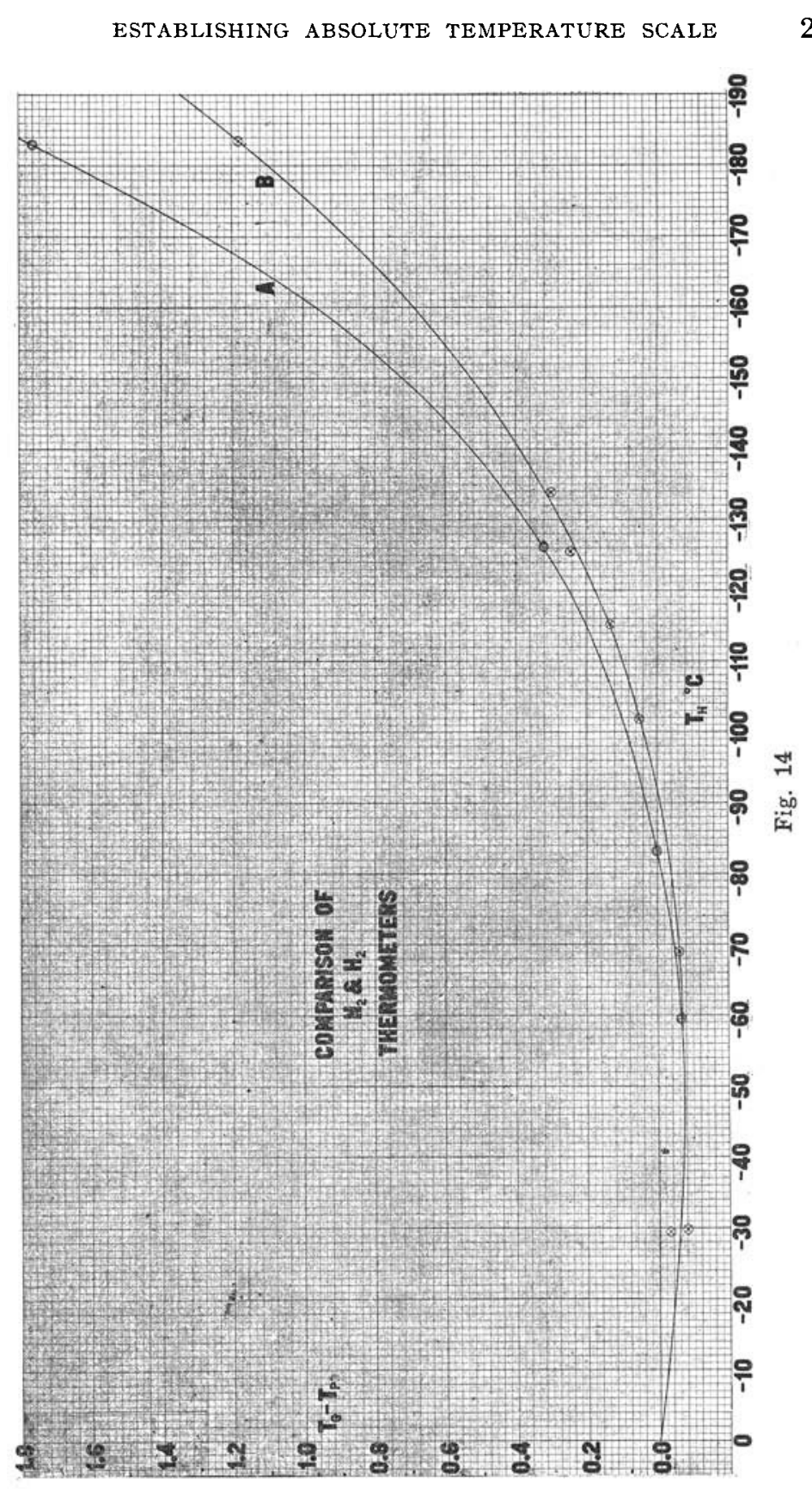


The deviations of a platinum resistance thermometer must be, to a certain extent, dependent upon the particular instrument employed, since they are certainly in part caused by strains in the wire, due to unequal contraction on its support Thus the results of Henning and the above measurements clearly indicate a large deviation of the platinum resistance thermometer at low temperatures of the approximate magnitude given, and, furthermore, that the deviations of any particular instrument must be independently investigated A type of support which would not set up strains in the wire under large temperature changes would be a great advantage, and the deviations of an instrument so constructed might possibly possess a considerable degree of generality

TABLE XVI

Comparison of Platinum Resistance Thermometer with Hydrogen Thermometer

\begin{tabular}{c|c|c|c|c|c|c}
\hline & \multicolumn{2}{|c|}{ Pressure } & & $t_{H,}$ & $t_{p t}$ & $t_{H_{2}-t_{p t}}$ \\
\cline { 2 - 7 } Date & $\begin{array}{c}P_{\circ} \\
m m\end{array}$ & $\begin{array}{c}P_{t} \\
\text { Reststance } \\
\text { ohms }\end{array}$ & ${ }^{\circ} \mathrm{C}$ & ${ }^{\circ} \mathrm{C}$ & ${ }^{\circ} \mathrm{C}$ \\
\hline $4 / 6 / 22$ & 76320 & 596.93 & 194758 & -5948 & -5941 & -007 \\
$4 / 6 / 22$ & 76320 & 53089 & 170288 & -8311 & -8311 & 0 \\
$4 / 6 / 22$ & 76320 & 41067 & 125120 & -126.12 & -12644 & +032 \\
$3 / 20 / 22$ & 76323 & 25167 & 6.348 & -18301 & -18485 & +184 \\
$3 / 20 / 22$ & 76323 & 25177 & 6352 & -18297 & -18481 & +184 \\
$3 / 20 / 22$ & 763.23 & 25180 & 6354 & -18296 & -18479 & +183 \\
$3 / 30 / 22$ & 76317 & 25282 & 6386 & -18260 & -18436 & +176 \\
$3 / 30 / 22$ & 76316 & 25257 & 6377 & -18268 & -18445 & +177 \\
\hline \hline
\end{tabular}

Comparison of Nitrogen and Hydrogen Thermometers

The platinum resistance thermometer having been carefully compared with the nitrogen and hydrogen thermometers under exactly similar conditions, we are now in a position to find the deviations of the nitrogen scale from that of hydrogen These can be found directly from Fig 14 and are, for convenience, tabulated in Table XVII As had been expected from the previous measurements with the nitrogen thermometer, there is no difference in the indications of the two instruments down to $-70^{\circ} \mathrm{C}$ At $-80^{\circ}$ the difference amounts to $002^{\circ}$ and increases more and 
more rapidly with lowering temperatures unt1 at the oxygen point it becomes $060^{\circ}$ Furnished with these deviations we can now correct all temperatures measured with the thermocouple to the scale of the hydrogen thermometer

The deviations of the nitrogen thermometer from the hydrogen scale will be ascribed, by those familiar with gas thermometry, to a property of the gas itself; although there is difficulty in explaining the difference of $060^{\circ}$ at $-183^{\circ}$ in view of the fact that the Berthelot correction at this temperature and initial pressure would be somewhat less than $04^{\circ}$ The usual interpretation is rejected, however, in view of the facts presented Within the limits of

TABLE XVII

Deviations of the Nitrogen Thermometer from the Hydrogen Scale

\begin{tabular}{c|c|c|c}
\hline \hline${ }^{t H_{2}}$ & ${ }^{t_{H_{2}}-t_{N_{2}}}$ & ${ }^{t_{H_{2}}}$ & ${ }^{t_{H_{2}}-t_{N_{2}}}$ \\
\hline-70 & +001 & ${ }^{\circ} \mathrm{C}$ & +014 \\
-80 & +002 & -140 & +019 \\
-90 & +004 & -160 & +0.28 \\
-100 & +005 & -170 & +040 \\
-110 & +006 & -180 & +055 \\
-120 & +008 & -183 & +060 \\
-130 & +010 & & \\
\hline
\end{tabular}

experimental measurements it has been found that the isometrics of gases sufficiently removed from their condensation points are straight lines Direct experumental evidence, moreover, of a thermodynamic correction could not be found, in that the indications of the nitrogen thermometer at $-183^{\circ} \mathrm{C}$ were independent of a large change in the initial pressure Other possible causes of the divergence in the two gas thermometers are evident since condensible impurities in the gas, association, and adsorption would all cause a similar effect Inasmuch as the gas was carefully prepared and passed through liquid air before being admitted to the bulb, the possibility of condensible impurities in sufficient amount to seriously affect the results must be ruled out At $-183^{\circ}$ and a pressure of a third of an atmosphere the gas is still far enough from its condensation point to make it improbable that association of the molecules could more than partly account 
for the deviations That adsorption takes place at low temperatures is well known, and it is of interest to form an estimate of how much adsorption would be necessary to explain the observed deviation The area of the bulb is approximately $120 \mathrm{sq} \mathrm{cm}$ and taking the area occupred by one molecule to be $\left(3 \times 10^{-8}\right)^{2}$ it is found that there would be $133 \times 10^{16}$ molecules in one adsorbed layer This corresponds to $614 \times 10^{-6}$ grams per layer If the pressure is decreased by $\Delta p$ due to adsorption. the total fraction of gas adsorbed is $\Delta p / p$ The total number of grams adsorbed to produce a lowering of the pressure by $\Delta p$ will then be $\frac{\Delta p}{R T} v$ or $31.5 \frac{\Delta p}{T}$ Hence the number of layers necessary to account for the effect is $\frac{315}{614 \times 10^{-6}} \frac{\Delta p}{T}=513 \times 10^{6} \frac{\Delta p}{T}$, where $\Delta_{p}$ is expressed in atmospheres

\begin{tabular}{|c|c|c|c|}
\hline \multicolumn{4}{|c|}{$\begin{array}{c}\text { TABLE XVIII } \\
\text { Adsorption of Nitrogen }\end{array}$} \\
\hline \multicolumn{4}{|c|}{$L=513 \times 10^{6} \frac{\Delta p}{T}$} \\
\hline$T_{H}$ Degrees Kelvin & $T_{H}-T_{N}$ & $\Delta P m m$ & Number of Lavers \\
\hline $\begin{array}{r}203 \\
193 \\
183 \\
173 \\
163 \\
153 \\
143 \\
133 \\
123 \\
113 \\
103 \\
93 \\
90\end{array}$ & $\begin{array}{l}01 \\
.02 \\
.04 \\
05 \\
06 \\
.08 \\
.10 \\
.14 \\
.19 \\
.28 \\
.40 \\
.55 \\
61\end{array}$ & $\begin{array}{r}03 \\
.05 \\
.11 \\
.13 \\
.16 \\
21 \\
.27 \\
37 \\
.51 \\
75 \\
107 \\
147 \\
163\end{array}$ & $\begin{array}{r}1 \\
2 \\
4 \\
5 \\
7 \\
9 \\
13 \\
19 \\
28 \\
45 \\
70 \\
106 \\
122 \\
\end{array}$ \\
\hline
\end{tabular}

In Table XVIII are given the number of layers of nitrogen adsorbed necessary to account for the deviation of the nitrogen from the hydrogen thermometer on the assumption that adsorption is negligible in the latter case These must be regarded as 
maximum values since the area of the bulb surface calculated from its dimensions is a lower limit The effective area for adsorption may be several times as great owing to the unevenness of the surface with respect to molecular dimensions Thus it would not be unreasonable to suppose that due to this circumstance the deviation at $-183^{\circ} \mathrm{C}$ might be accounted for by adsorption to a depth of only thirty or forty layers Whether adsorption of nitrogen and other gases on quartz at low temperatures takes place to such an extent is of course an open question No reliable data are at hand Langmu1r, ${ }^{39}$ however, found that glass and mica strongly adsorbed nitrogen at liquid air temperatures at only $01 \mathrm{~mm}$ pressure, while the adsorption of hydrogen he found to be very much less It thus appears that the deviation of the nitrogen

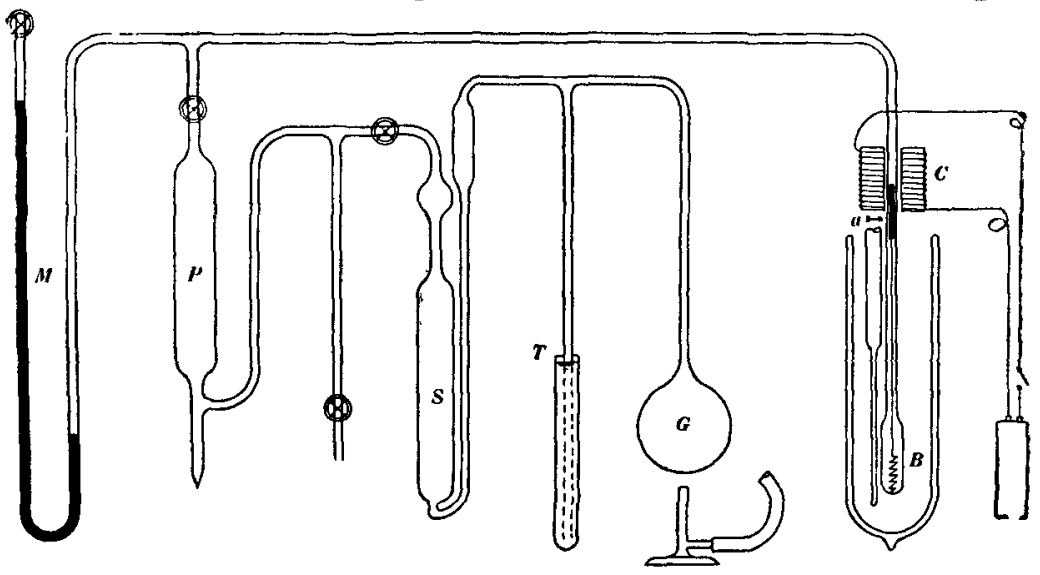

Fig. 15

thermometer from the hydrogen scale at low temperatures finds a ready explanation in the combined effects of adsorption and association* Of these two the former would appear to be the larger In the case of the hydrogen thermometer the indications are that any error due to adsorption at liquid air temperatures is extremely small.

39 Langmu1r, J. Am. Ch Soc. 39, 1917.

*That variation of the inital pressure is without effect is due to adsorption being independent of the pressure above a certain point. Thus, on metals the amount of gas adsorbed remains constant above a pressure of $300 \mathrm{~mm}$. according to Taylor and Burns, J. Am Ch. Soc., 43, p 1273, 1921 


\section{The Bonlung Pount of Oxygen}

A determination of the boiling point of oxygen based on the nitrogen thermometer has already been noted It is now possible to transfer this to the hydrogen (thermodynamic) scale The determination was carried out by means of the apparatus shown in Fig 15 The oxygen was prepared in $G$ by the decompostion of potassium permanganate It was passed through sodium hydroxide (20 per cent) $S$, and phosphorus pentoxide $P$ and condensed in the bulb $B$ (ca $10 \mathrm{cc}$ ) surrounded by liquid air The tube $T$, dipping into mercury, acted as a valve, limiting the pressure to about ninety centimeters of mercury The liquid in $B$ could be electromagnetically stirred by means of the iron stirrer $a$ and the conls $C$ The vapor pressure of the liquid was read directly on the manometer $M$ and its temperature found with the platinum resistance thermometer. The apparatus was exhausted and swept out several times with oxygen before proceeding with the measurements To test the puraty of the oxygen about one-half of the liquid in $B$ was allowed to evaporate and the vapor pressure of the remainder determined, being found to give the same value as before

The normal bolling point of oxygen thus found is $18294^{\circ} \mathrm{C}$, the details of the measurements being given in Table XIX The agreement of our value with the latest value of Onnes, ${ }^{\mathbf{4 0}}-18293^{\circ}$ C (or $-18297^{\circ}$ uncorrected), is excellent

TABLE XIX

Oxygen Boiling Point

\begin{tabular}{c|c|c|c|c|c}
\hline & $t_{p t .}$ & ${ }^{t_{H_{Q}}}$ & $\begin{array}{c}\text { Vapor } \\
\text { Pressure } \\
m m\end{array}$ & $\begin{array}{c}\frac{\Delta p^{2}}{\Delta t} \\
m m / d e g .\end{array}$ & ${ }^{\circ}{ }^{\circ} \mathrm{C} P$. \\
\hline $12 / 23 / 21$ & -18441 & -18264 & 7844 & 818 & -18294 \\
$12 / 23 / 21$ & -18436 & -18260 & 7879 & 823 & -18294 \\
\hline
\end{tabular}

The Boulnng Point of Carbon Dioxide

The boiling point of carbon dioxide was determined in the same vapor pressure manometer that was used for oxygen The gas

40 Cath, Leiden Comm., 152d, see Note 1, p 48 
was prepared by the decomposition of sodium bicarbonate and dried with phosphorus pentoxide The bulb (Fig 15) was immersed in a freezing mixture of carbon dioxide snow and ether, whereupon the carbon dioxide condensed in the form of perfectly clear ice. The vapor pressure was found independent of the amount of substance, thus attesting to its purity Observations were taken at a pressure of $7202 \mathrm{~mm}$ and the bojling point at this pressure was found to be $-7919^{\circ} \mathrm{C}$ on the hydrogen scale This is in excellent agreement with the value of $-7918^{\circ} \mathrm{C}$ given by the formula of Henning ${ }^{37}$ The deta1ls of the measurements follow:

Boiling Point of Carbon Dioside

\begin{tabular}{c|c|c|c|c|c}
\hline Date & $t_{p t}$ & $t_{H_{2}}$ & $\begin{array}{c}\text { Vapor } \\
\text { Pressure } \\
m m\end{array}$ & $\begin{array}{c}\frac{\Delta p}{\Delta t} \\
m m / \text { deg. }\end{array}$ & $\begin{array}{c}\text { N.B.P. } \\
{ }^{\circ} \mathrm{C}\end{array}$ \\
\hline $1 / 12 / 22$ & -79.17 & -79.17 & 7202 & 603 & -7853 \\
\hline
\end{tabular}

\section{Part II}

Freezing Points of Certain Organc Liquds and of Mercury and Ammonia

Certain freezing points have been measured in the range from $0^{\circ} \mathrm{C}$ to $-123^{\circ} \mathrm{C}$ in order to establish fixed points for thermometric comparison The temperatures were obtained with the multiple copper-constantan thermocouple described in Part I, p 290, which had been repeatedly calibrated directly against the nitrogen constant volume thermometer A direct comparison of the nitrogen and hydrogen thermometers enables us to give the freezing points directly on the constant volume hydrogen, or thermodynamic, scale

\section{The Method}

The electrical circurt has been described as noted above The hquid whose freezing point is to be determined is contaned in the double-walled vessel $A$ ( $F_{1} g$ 16A), $2 \mathrm{~cm}$ in diameter and 13 $\mathrm{cm}$ long The space between the walls of this vessel is connected to the vacuum pump and can be exhausted to any desired degree, thus controlling the rate of cooling Cooling is obtained by liquid 
air in the outer Dewar tube $B$ The liqu1d is stirred by a stream of dry air entering through the fine glass tube $S$, further serving to keep the space above the liqu1d free of moisture It was found that the freezing points were independent of the rate of stirring between wide limits, but that some stirrng was necessary to give concordant results In determining the freezing points of organic liqu1ds a thermocouple possesses a marked advantage in that it records the temperature at a definite point The thermal conductivity of the two phase mixtures is so low that it is practically impossible to secure uniformity of temperature throughout a large mass of the liquid as the freezing point is approached and an instrument of considerable bulk will consequently register an average temperature which may not be the true freezing point, at least in those cases where ice forms first at the bottom of the tube and builds upward

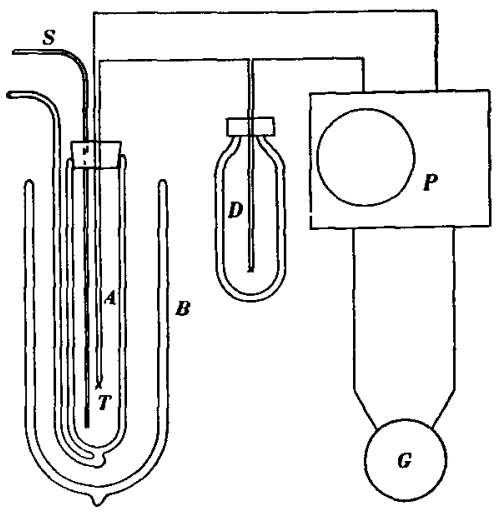

Fig. 16a

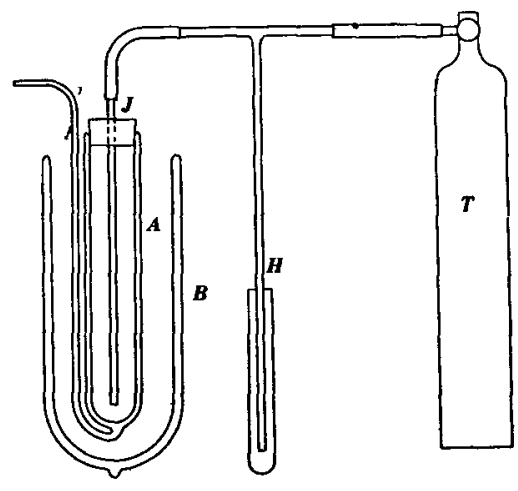

Fig. 16b

In determining the freezing points of liquids which are gaseous at ordinary temperatures, such as methyl chloride and ammonia, the tube $A$ was first well cooled, whereupon the gas from the supply $T$ (Fig 16B) was admitted through the glass tube $J$. It then rapidly liquefied under the slight excess of pressure The tube $H$, dipping into mercury, prevented the pressure from becoming more than a few centimeters of mercury above atmospheric 


\section{The Results}

The individual determinations are given in Tables XX-XXX. The methods of purification, starting with the best $\mathrm{C} \mathrm{P}$ chem1cals obtainable, are also given * Column 5 gives the average cooling rate durng the five minutes preceding freezing The freezing points of mercury, ammonia, and methyl chloride are easily reproducible and constitute the most satisfactory fixed points The ammonia point was likewise measured with the platinum resistance thermometer, the two methods agreeing within $001^{\circ} \mathrm{C}$ In some measurements a silvered tube was used in place of the clear glass Dewar tube $A$ without affecting the results $\mathrm{A}$ considerable variation in the dimensions of the freezing point tube was likewise without effect on the constancy of the freezing points The freezing point found for an organic liquid depends somewhat upon the method employed and the thoroughness of the purification The results here given will be found reproducible provided the general method of procedure is followed

In Table XXXI the various fixed points are summarized, including the determinations of the bolling points of carbon dioxide and oxygen recorded in Part I For the sake of comparison the results of other investrgators are also given

TABLE XX

Carbon Tetrachloride $\dagger$

$\mathrm{CCl}$.

\begin{tabular}{c|c|c|c|c}
\hline & $\begin{array}{c}E M F \\
\text { Date }\end{array}$ & $\begin{array}{c}\text { Time } \\
\text { Minutes }\end{array}$ & $\begin{array}{c}\text { Cooling Rate } \\
\text { Deg /Min. }\end{array}$ & $\begin{array}{c}\text { Freezing Point } \\
{ }^{\circ} C\end{array}$ \\
\hline $5 / 25 / 21$ & 4957 & 8 & 067 & -2285 \\
$5 / 25 / 21$ & 4962 & 9 & 073 & -2286 \\
$6 / 6 / 21$ & 4960 & 7 & 0.77 & -22.86 \\
$6 / 6 / 21$ & 4959 & 7 & 103 & -22.86 \\
$6 / 6 / 21$ & 4965 & 5 & 214 & -2289 \\
$6 / 6 / 21$ & 4966 & 5 & 244 & -2289 \\
\hline
\end{tabular}

* The chemicals were kindly prepared by Mr. R. S. Taylor of the Research Laboratory of Physical Chemistry

$\dagger$ Purification. Warm with alcohol and caustic potash to remove $\mathrm{CS}_{2}$ and $S \mathrm{Cl}_{2}$. Remove alcohol by shaking with water. Remove water over caustic potash and finally over sodium, lastly distill over paraffin, whereby the small quantity of perchlorethane is held back. 
TABLE XXI

Mercury*

Hg.

\begin{tabular}{c|c|c|c|c}
\hline \multicolumn{1}{c|}{ Date } & $\begin{array}{c}E . M F \\
10^{-6} \text { Volts }\end{array}$ & $\begin{array}{c}\text { Time } \\
\text { Minutes }\end{array}$ & $\begin{array}{c}\text { Cooling Rate } \\
\text { Deg./Min. }\end{array}$ & $\begin{array}{c}\text { Freezing Point } \\
{ }^{C} \mathrm{C}\end{array}$ \\
\hline $6 / 24 / 21$ & 8264 & Indefinite & 1.29 & -3890 \\
$6 / 24 / 21$ & 8264 & Indefinite & 1.57 & -38.90 \\
$8 / 30 / 21 \dagger$ & 8262 & Indefinte & 151 & -3889 \\
$8 / 30 / 21 \dagger$ & 8264 & Indefinite & 098 & -3890 \\
\hline
\end{tabular}

* Purnfication. Agitate with dilute nitric acid and distill several times.

$\dagger$ Silvered tube

TABLE XXII

Chlorbenzene*

$\mathrm{C}_{6} \mathrm{H}_{5} \mathrm{Cl}$

\begin{tabular}{c|c|c|c|c}
\hline Date & $\begin{array}{c}E . M F \\
\times 10^{-9} \text { Volts }\end{array}$ & $\begin{array}{c}\text { Time } \\
\text { Minutes }\end{array}$ & $\begin{array}{c}\text { Cooling Rate } \\
\text { Deg } / \text { Mmn. }\end{array}$ & $\begin{array}{c}\text { Freezing Point } \\
{ }^{\circ} \mathrm{C}\end{array}$ \\
\hline $5 / 16 / 21$ & 9590 & 31 & 240 & -4558 \\
$5 / 17 / 21$ & 9584 & 30 & 179 & -4553 \\
$6 / 7 / 21$ & 9595 & 10 & 317 & -4562 \\
$6 / 7 / 21 \dagger$ & 9590 & 12 & 365 & -4558 \\
$6 / 7 / 21$ & 9590 & 50 & 289 & -4558 \\
$6 / 9 / 21 \dagger$ & 9590 & 10 & 104 & -4558 \\
$8 / 26 / 21 \dagger$ & 9589 & 5 & 254 & -4557 \\
\hline
\end{tabular}

* Purification. Wash with water and dilute $\mathrm{NaOH}$. Dry over $\mathrm{CaCl}_{2}$ and distill with fractionating column three or four times Dry over metallic sodium and again distill.

$\dagger$ Silvered tube

TABLE XXIII

Chloroform*

$\mathrm{CHCl}_{3}$

\begin{tabular}{c|c|c|c|c}
\hline \hline Date & $\begin{array}{c}\text { E M.F. } \\
10^{-6} \text { Volts }\end{array}$ & $\begin{array}{c}\text { Time } \\
\text { Minutes }\end{array}$ & $\begin{array}{c}\text { Cooling Rate } \\
\text { Deg /Min. }\end{array}$ & $\begin{array}{c}\text { Freezing Point } \\
{ }^{C} \text { C }\end{array}$ \\
\hline $5 / 20 / 21$ & 13141 & 2 & 1.34 & -64.15 \\
$5 / 20 / 21$ & 13160 & 8 & 005 & -6424 \\
$5 / 20 / 21$ & 13147 & 12 & 211 & -6417 \\
$5 / 20 / 21$ & 13134 & 3 & 082 & -6411 \\
$6 / 8 / 21$ & 13151 & 2 & 1.67 & -6420 \\
$6 / 8 / 21$ & 13160 & 2 & 213 & -6424 \\
$6 / 8 / 21$ & 13149 & 3 & 103 & -64.18 \\
$6 / 9 / 21$ & 13157 & 4 & 104 & -64.23 \\
$6 / 9 / 21$ & 13154 & 8 & 1.48 & -64.21 \\
$6 / 9 / 21$ & 13154 & 3 & 156 & -6421 \\
\hline \hline
\end{tabular}

* Purification. Agitate with pure concentrated $\mathrm{H}_{2} \mathrm{SO}_{4}$ until the ac1d is no longer colored. Next wash with $\mathrm{Na}_{2} \mathrm{CO}_{3}$ and then with alkaline permanganate. Wash with distilled water, dry over sodium and distill 
TABLE XXIV

Ammonia*

$\mathrm{NH}_{3}$

\begin{tabular}{|c|c|c|c|c|}
\hline Date & $\begin{array}{c}\text { E.MF } \\
10^{-6} \text { Volts }\end{array}$ & $\begin{array}{c}\text { Time } \\
\text { Minutes }\end{array}$ & $\begin{array}{l}\text { Coolıng Rate } \\
\text { Deg / Min. }\end{array}$ & Freezing Point \\
\hline $\begin{array}{l}6 / 20 / 21 \\
6 / 20 / 21 \\
8 / 25 / 21 \dagger \\
8 / 25 / 21 \dagger \\
\end{array}$ & $\begin{array}{l}15634 \\
15634 \\
15635 \\
15634 \\
\end{array}$ & $\begin{array}{r}28 \\
25 \\
6 \\
33 \\
\end{array}$ & $\begin{array}{ll}0 & 81 \\
0 & 80 \\
1 & 28 \\
105 \\
\end{array}$ & $\begin{array}{r}-7780 \\
-7780 \\
-7780 \\
-7780 \\
\end{array}$ \\
\hline
\end{tabular}

* Purnfication Dry with sodium.

$\dagger$ Silvered tube.

TABLE XXV

Toluene*

$\mathrm{C}_{6} \mathrm{H}_{5} \mathrm{CH}_{3}$

\begin{tabular}{c|c|c|c|c}
\hline \hline Date & $\begin{array}{c}E M F \\
10^{-6} \text { Volts }\end{array}$ & $\begin{array}{c}\text { Time } \\
\text { Minutes }\end{array}$ & $\begin{array}{c}\text { Coolıng Rate } \\
\text { Deg./Min }\end{array}$ & $\begin{array}{c}\text { Freezing Point } \\
{ }^{C} C\end{array}$ \\
\cline { 2 - 4 } & 18729 & 5 & 076 & -95.71 \\
$5 / 13 / 21$ & 18730 & 5 & 128 & -95.71 \\
$5 / 16 / 21$ & 18730 & 4 & 0.79 & -95.71 \\
$5 / 31 / 21$ & 18723 & 4 & 2.33 & -95.67 \\
$6 / 4 / 21$ & 18726 & 13 & 1.58 & -95.68 \\
$6 / 22 / 21 \dagger$ & 18734 & 13 & 0.71 & -95.73 \\
$6 / 22 / 21$ & 18730 & 10 & 1.21 & -95.71 \\
$7 / 19 / 21$ & 18728 & 6 & 1.58 & -95.70 \\
$7 / 19 / 21$ & 18726 & 11 & 1.27 & -95.69 \\
$8 / 31 / 21 \dagger$ & 18727 & 12 & 057 & -9569 \\
\hline
\end{tabular}

* Purification. Free of phenols by $\mathrm{NaOH}$. Shake with concentrated $\mathrm{H}_{2} \mathrm{SO}_{4}$ until ac1d is no longer colored. Agitate with mercury until it ceases to pollute a clean $\mathrm{Hg}$ surface Wash and distill several times. Dry with $\mathrm{CaCl}_{2}$ and sodium.

$\dagger$ Silvered tube

TABLE XXVI

Methyl Chloride*

$\mathrm{CH}_{3} \mathrm{Cl}$

\begin{tabular}{c|c|c|c|c}
\hline \hline Date & $\begin{array}{c}E M F \\
10^{-6} \text { Volts }\end{array}$ & $\begin{array}{c}\text { Time } \\
\text { Minutes }\end{array}$ & $\begin{array}{c}\text { Cooling Rate } \\
\text { Deg/Min. }\end{array}$ & $\begin{array}{c}\text { Freezing Point } \\
{ }^{\circ} C\end{array}$ \\
\hline $6 / 23 / 21$ & 19172 & 5 & 128 & -9839 \\
$6 / 23 / 21$ & 19172 & 11 & 084 & -9839 \\
\hline
\end{tabular}

* Taken from the top of a tank of the commercially pure gas 
TABLE XXVII

Methyl Alcohol* $\mathrm{CH}_{3} \mathrm{OH}$

\begin{tabular}{c|c|c|c|c}
\hline \hline & $\begin{array}{c}E M F \\
10^{-6} \text { Volts }\end{array}$ & $\begin{array}{c}\text { Time } \\
\text { Minutes }\end{array}$ & $\begin{array}{c}\text { Coolıng Rate } \\
\text { Deg /Min. }\end{array}$ & $\begin{array}{c}\text { Freezıng Point } \\
{ }^{\circ} \mathrm{C}\end{array}$ \\
\hline $6 / 17 / 21$ & 19197 & 6 & 101 & -9854 \\
$6 / 17 / 21$ & 19194 & 8 & 103 & -9853 \\
\hline \hline
\end{tabular}

* Purification Treat with iodine and then with slight excess $\mathrm{NaOH}$. Reflux over fresh quicklime and finally dry with metallic calcium. Keep moist air away.

TABLE XXVIII

Carbon Disulphide*

$\mathrm{CS}_{2}$

\begin{tabular}{c|c|c|c|c}
\hline \hline Date & $\begin{array}{c}\text { E.MF. } \\
10^{-6} \text { Volts }\end{array}$ & $\begin{array}{c}\text { Time } \\
\text { Minutes }\end{array}$ & $\begin{array}{c}\text { Cooling Rate } \\
\text { Deg./Min. }\end{array}$ & Freezing Pount \\
\hline $6 / 16 / 21$ & 21484 & 2 & 254 & -11296 \\
$6 / 16 / 21$ & 21486 & 3 & 249 & -11297 \\
$6 / 16 / 21$ & 21483 & 4 & 062 & -11295 \\
$6 / 17 / 21$ & 21488 & 3 & 040 & -112.97 \\
$8 / 27 / 21 \dagger$ & 21491 & 8 & 110 & -11300 \\
$8 / 27 / 21 \dagger$ & 21488 & 5 & 068 & -11298 \\
\hline
\end{tabular}

* Purificalion. Digest with finely divided copper powder or with mercury over a water bath Distill repeatedly. Dry with $\mathrm{CaCl}_{2}$ and $\mathrm{Na}$.

$\dagger$ Silvered tube

\section{TABLE XXIX}

Ether*

$\left(\mathrm{C}_{2} \mathrm{H}_{5}\right)_{2} \mathrm{O}$

\begin{tabular}{c|c|c|c|c}
\hline & \multicolumn{2}{|c|}{ First Modification $\dagger$} & \\
\cline { 2 - 4 } Date & $\begin{array}{c}\text { EMF } \\
\times 10^{-6} \text { Volts }\end{array}$ & $\begin{array}{c}\text { Time } \\
\text { Minutes }\end{array}$ & $\begin{array}{c}\text { Cooling Rate } \\
\text { Deg /Min }\end{array}$ & Freezing Point \\
\hline $6 / 13 / 21$ & 23052 & 7 & 147 & -12340 \\
$6 / 15 / 21$ & 23052 & 27 & 158 & -12340 \\
$6 / 15 / 21$ & 23046 & 5 & 160 & -12336 \\
$6 / 15 / 21$ & 23054 & 28 & 176 & -12342 \\
$6 / 16 / 21$ & 23053 & 15 & 133 & -12341 \\
\hline
\end{tabular}

* Purification Shake with conc $\mathrm{H}_{2} \mathrm{SO}_{4}$ Then leave with $200 \mathrm{c}$ c of a sat sol of $K \mathrm{MnO}_{4}$ containing $20 \mathrm{gms}$ of $\mathrm{NaOH}$ per liter. After 24 hours decant and repeat Wash with water Let stand over $\mathrm{H}_{2} \mathrm{SO}$, shortly Dry over $\mathrm{CaCl}_{2}$, then distill and dry over sodium.

$\dagger$ The first modification occurred more often and gave the better point although the second modification is considered the more stable (see Table XXX) 


\begin{tabular}{|c|c|c|c|c|}
\hline \multirow[b]{2}{*}{ Date } & \multicolumn{2}{|c|}{ Second Modificainon } & \multirow[b]{2}{*}{$\begin{array}{c}\text { Coolnng Rate } \\
\text { Deg / Min. }\end{array}$} & \multirow[b]{2}{*}{ Freezing Point } \\
\hline & $\begin{array}{c}E . M F \\
\times 10^{-6} \text { Volts }\end{array}$ & $\begin{array}{c}\text { Time } \\
\text { Minutes }\end{array}$ & & \\
\hline $\begin{array}{l}6 / 13 / 21 \\
6 / 13 / 21 \\
6 / 15 / 21\end{array}$ & $\begin{array}{l}21890 \\
21921 \\
21990\end{array}$ & $\begin{array}{l}20 \\
39 \\
17\end{array}$ & $\begin{array}{l}\overline{037} \\
160\end{array}$ & $\begin{array}{l}-1156 \\
-1157 \\
-1163\end{array}$ \\
\hline
\end{tabular}

TABLE XXX

Detail of Ether Run Showing Both Modifications

$6 / 15 / 21$

\begin{tabular}{|c|c|c|c|c|c|c|c|}
\hline $\begin{array}{l}\text { Time } \\
2 n \\
\text { Min- } \\
\text { utes }\end{array}$ & $\begin{array}{c}\text { Reading } \\
\text { in } \\
\text { Microvolts }\end{array}$ & $\begin{array}{c}\text { Time } \\
\text { in } \\
\text { Min- } \\
\text { utes }\end{array}$ & $\begin{array}{c}\text { Reading } \\
\text { in } \\
\text { Microvolts }\end{array}$ & $\begin{array}{l}\text { Time } \\
\text { in } \\
\text { Min- } \\
\text { utes }\end{array}$ & $\begin{array}{c}\text { Reading } \\
\text { in } \\
\text { Microvolts }\end{array}$ & $\begin{array}{c}\text { Time } \\
\text { in } \\
\text { Min- } \\
\text { utes }\end{array}$ & $\begin{array}{c}\text { Reading } \\
\text { in } \\
\text { Microvolts }\end{array}$ \\
\hline 0 & 22395 & 8 & 23036 * & 16 & $21988 \dagger$ & 24 & $21991 \dagger$ \\
\hline 1 & 22650 & 9 & 23050 * & 17 & $21991 \dagger$ & 25 & $21993 \dagger$ \\
\hline 2 & 22859 & 10 & 21996 & 18 & $21990 \dagger$ & 26 & $21994 \dagger$ \\
\hline 3 & 23069 & 11 & $21987 \dagger$ & 19 & 21990 & 27 & $21992 \dagger$ \\
\hline 4 & $23243 *$ & 12 & $21987+$ & 20 & 21990 & 28 & $21991 \dagger$ \\
\hline 5 & 23054 * & 13 & 21990 & 21 & 21990 & 29 & 22010 \\
\hline 6 & 23039 * & 14 & 21991 & 22 & $21991 \dagger$ & 30 & 22064 \\
\hline 7 & 23049 * & 15 & 21991 & 23 & $21991 \dagger$ & 31 & 22164 \\
\hline
\end{tabular}

* One + Two 


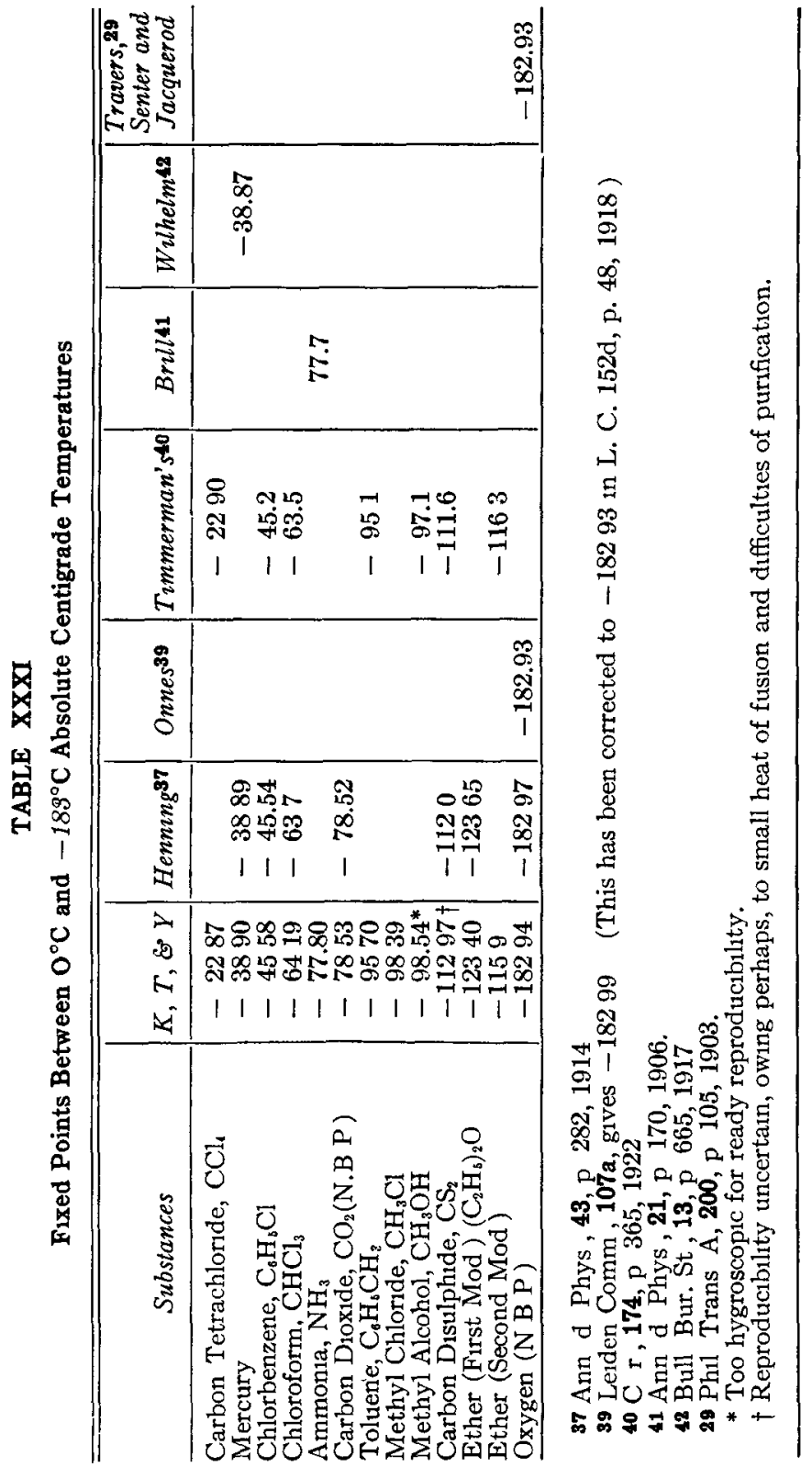




\section{Summary}

A discussion of the constant volume gas thermometer and its errors has been given Evidence has been cited leading to the conclusion that the pressure of a gas at constant volume is a linear function of the temperature, in which case the constant volume gas thermometer indicates directly on the thermodynamic scale This conclusion has been supported by first, an analysis of the 1sometrics of hydrogen calculated from the data of the Leiden laboratory, second, a recalculation of the boiling point of sulphur based on the data of the $\mathrm{H}_{2}, \mathrm{He}$ and $\mathrm{N}_{2}$ constant volume and the $\mathrm{N}_{2}$ constant pressure gas thermometers (mean N B P $44456^{\circ}$ ), in which the value obtained from the constant volume nitrogen thermometer of Holborn and Henning, recalculated using the expansion coefficient given by the equation of state for nitrogen, was found to agree almost exactly, without correction to the thermodynamic scale, with the constant pressure nitrogen value of Eumorfopoulos corrected to the thermodynamic scale in accordance with the Keyes equation of state for nitrogen and with the value of Holborn and Henning derived from the constant volume helium and hydrogen thermometers; third, by direct experiment in which the indications of a constant volume nitrogen thermometer at $-183^{\circ}$ were found independent of the initial pressure between 640 and $440 \mathrm{~mm}$

A constant volume hydrogen thermometer, capable of measuring temperatures with an accuracy of 001 per cent, has been described, together with a new form of cryostat in which low temperatures can be held constant to within $001^{\circ}$

The copper-constantan thermocouple has been calibrated against the gas thermometer and the deviations of the platinum resistance thermometer from the absolute scale determmed over the range from $0^{\circ}$ to $-183^{\circ}$ The platinum thermometer has been found to give too low a temperature at the boiling point of oxygen by about $16^{\circ}$, but the exact deviation depends upon the particular instrument employed

A direct comparison of the nitrogen and hydrogen constant volume thermometers showed no divergence between the two scales down to $-70^{\circ}$, while below this temperature the divergence 
gradually increases unt1l it amounts to $06^{\circ}$ at the boiling point of oxygen It has been shown that this divergence can be readily explained by the combined effects of association of the nitrogen and adsorption upon the walls of the quartz container

The normal boiling point of carbon dioxide has been found to be $-7853^{\circ} \mathrm{C}$ and that of oxygen $-18294^{\circ} \mathrm{C}$ A detaled account has been given of a method of determining freezing points of various substances in the interval from $-40^{\circ}$ to $-124^{\circ}$ to serve as fixed points for thermometric comparison These freezing points are.

\begin{tabular}{|c|c|c|}
\hline Carbon Tetrachlonde, $\mathrm{CCl}$ & & -2287 \\
\hline Mercury & & -3890 \\
\hline Chlorbenzene, $\mathrm{C}_{6} \mathrm{H}_{5} \mathrm{Cl}$ & & -4558 \\
\hline Chloroform, $\mathrm{CHCl}_{3} \ldots$ & . & -6419 \\
\hline Ammonia, $\mathrm{NH}_{3} \quad \ldots$ & & -7780 \\
\hline Toluene, $\mathrm{C}_{6} \mathrm{H}_{5} \mathrm{CH}_{3}$. & $\cdots$ & -9570 \\
\hline Methyl Chloride, $\mathrm{CH}_{3} \mathrm{Cl}$ & & -9839 \\
\hline Methyl Alcohol, $\mathrm{CH}_{3} \mathrm{OH}$ & & -9854 \\
\hline Carbon Disulphide, $\mathrm{CS}_{2}$ & & -11297 \\
\hline Ether $\left(\mathrm{C}_{2} \mathrm{H}_{5}\right)_{2} \mathrm{O}$, I Mod & . & -12340 \\
\hline Ether, II Mod. & & -1159 \\
\hline
\end{tabular}

Helium has been found to diffuse too readily through quartz at room temperatures to permit of its convenient use in a thermometer bulb of this material. Hydrogen likewise has been found to diffuse through quartz at ordinary temperatures, but so slowly as not to interfere with its use in quartz for low-temperature thermometry 